Article Title: Reconsidering the Donohue-Levitt Hypothesis

\title{
Samuel Kahn
}

Abstract. According to the Donohue-Levitt hypothesis, the legalization of abortion in the United States in the 1970s explains some of the decrease in crime in the 1990s. In this paper, I challenge this hypothesis. First, I argue against the intermediate mechanisms whereby abortion in the 1970s is supposed to cause a decrease in crime in the 1990s. Second, I argue against the correlations that support this causal relationship.

I.

Introduction. According to the Donohue-Levitt hypothesis, there is a causal connection between the legalization of abortion in the United States in the 1970s and the steady decrease in crime in the 1990s. In this paper, I argue for the following two theses: (1) a plausible mechanism for this connection has not been offered and (2) the evidence for the connection is suggestive but inconclusive. The paper is divided into two main sections. In the first, I argue for my first thesis. I canvass some of the main mechanisms proposed and explain why I do not think they withstand critical scrutiny. In the second, I argue for my second thesis. I review some of the major evidence for the connection and argue that although there are some suggestive correlations, the balance of evidence militates against the Donohue-Levitt hypothesis. Although my conclusion could serve to undermine a key premise in a popular utilitarian argument in favor of abortion, I shall not be taking a stand on the morality of abortion or on any of the issues surrounding abortion laws (e.g., timing, government funding, etc.). 
A.

The Mechanisms. In order to understand the Donohue-Levitt hypothesis, it is useful to note two facts. First, reported rates of legal abortions began steadily to increase in the United States in the 1970s. A few states made abortion legal under limited circumstances in the late 1960s and early 1970s. ${ }^{1}$ But it was not until Roe v. Wade (in 1973) that

${ }^{1}$ Donohue and Levitt note that between 1967 and 1970, 13 states provided for legal abortion under three conditions: (1) to prevent death or grave mental or physical impairment to the mother; (2) if the fetus would be born with grave mental or physical defect; and (3) in the case of rape or incest. The states were: Arkansas, California, Colorado, Delaware, Florida, Georgia, Kansas, Maryland, New Mexico, North Carolina, Oregon, South Carolina and Virginia (John Donohue and Steven Levitt, "The impact of legalized abortion on crime," The Quarterly Journal of Economics 116.2 (2001): $379-420$, at 383n4). In addition, five states repealed their antiabortion laws during this same time period, making abortion more broadly available. These states were: Alaska, California, Hawaii, New York and Washington (ibid., at 383-4). Donohue and Levitt refer to these five states as the "early repeal" states. Joyce argues that D.C. should be included among the early repealers (Ted Joyce, “Did legalized abortion lower crime?” The Journal of Human Resources 39.1 (Winter, 2004): 1-28, at 4n2). 
abortion became legal everywhere in the United States. ${ }^{2}$ Second, violent crime, property crime and homicide, perhaps the most reliably measured kind of violent crime, began steadily to decrease in the United States in the 1990s. Putting these two facts together, it may be seen that there seems to be an inverse relationship between abortion rates and crime rates about 20 years later: about 20 years after abortion rates began to increase, crime rates began to decrease. ${ }^{3}$

According to the Donohue-Levitt hypothesis, if these abortions had not taken place, then the resulting children would have increased the crime rates when they grew up. That is, the causal connection between abortion and crime posited in the Donohue-Levitt hypothesis is not about, for example, the kinds of attitudes and values that might (or might not) be promulgated through a society by means of a change in abortion law. Rather, the Donohue-Levitt hypothesis is about what the counterfactual children would have gone on to do with their lives if they had been carried to term. The fact that the

${ }^{2}$ This is an oversimplification. For one thing, it is consistent with Roe v. Wade for a state to outlaw third trimester elective abortions. For another thing, not all states are in compliance with Roe v. Wade. Finally, there is an important distinction between a woman being legally permitted to get an abortion and a woman having access to abortion services. Some of these issues are addressed below. For now, I am trying to paint the bigger picture.

${ }^{3}$ This is illustrated in figures 12a, 12b and 12c from Angela Dills, Jeffrey Miron and Garret Summers, “What do economists know about crime?” NBER Working Paper Series Working Paper 13759. 
correlation shows up around the 20 year mark is, according to Donohue and Levitt, important: adolescents around the age of 20 are taken to be in their high crime years, so not having them around will have a measurable impact on crime rates.

There are two main mechanisms through which legalized abortion is taken to lower crime. The first has to do with cohort size (quantity). Even if the fetuses that are aborted have the same chances of becoming criminals as those which are carried to term, the fact that an abortion results in one less baby means that there will be one less potential criminal 20 years later. The second mechanism has to do with selection effects (quality). If the fetuses that are aborted are at greater risk of becoming criminals (e.g., because of the environment in which they would have grown up) than those which are carried to term, then even if the cohort size stays the same, there will be fewer criminals. These two mechanisms are not mutually exclusive: legalizing abortion might reduce crime by bringing about a smaller cohort whose members are at lower risk of becoming criminals than the aborted fetuses would have been.

Before I discuss these mechanisms in greater detail, I want to make two points. First, both of these mechanisms have been appealed to in other discussions of crime trends. For example, Blumenstein, Cohen and Miller used demographic data to predict 
that crime levels would decrease in the 1980s because of smaller cohort sizes. ${ }^{4}$ Similarly, DiIulio predicted that crime would rise from the mid-1990s through the mid-2000s based in part on the qualities of the cohort that would be coming of age. ${ }^{5}$ The word "superpredator" was coined in this discussion to refer to a youth who, perhaps because of a bad upbringing, has unusually high criminogenic propensities.

Second, selection effects from legalizing abortion have been appealed to outside of discussions of crime trends. For example, Gruber, Levine and Staiger observe that legalizing abortion could have selection effects in at least two different ways. On the one hand, if women use abortion to avoid bearing children into adverse conditions, then positive selection will result; on the other hand, if the most disadvantaged women are

\footnotetext{
${ }^{4}$ Alfred Blumstein, Jacqueline Cohen, Harold Miller, "Demographically disaggregated projections of prison populations," Journal of Criminal Justice 8.1 (1980): 1-26. It should be noted that their model also appeals to demographic changes in the composition of the cohort: it is not purely based on cohort size. But the fact that cohort size has played a role in these debates (independently of the Donohue-Levitt hypothesis) is all that I am trying to establish.

${ }^{5}$ John DiIulio, “The Coming of the Super-Predators,"The Weekly Standard 1.11 (Nov. 27, 1995).
} 
constrained in their abortion access, then negative selection will result. ${ }^{6}$ In order to determine whether positive or negative selection is more prevalent, Gruber, Levine and Staiger use data from the 5 percent Public Use Micro Sample of the 1980 Census and the U.S. Vital Statistics. They conclude:

...the marginal children who were not born as a result of abortion legalization would have systematically been born into less favorable circumstances if the pregnancies had not been terminated: they would have been 60 percent more likely to live in a single-parent household, 50 percent more likely to live in poverty, 45 percent more likely to be in a household collecting welfare, and 40 percent more likely to die during the

\footnotetext{
${ }^{6}$ Jonathan Gruber, Phillip Levine and Douglas Staiger, “Abortion Legalization and Child Living Circumstances: Who is the 'Marginal Child'?" The Quarterly Journal of Economics 114.1 (Feb., 1999): 263-91, especially p. 264: “On the one hand, if women use abortion to avoid bearing children into adverse circumstances, positive selection would result: the living circumstances of the marginal child are not so good as those of the average child, so that increased abortion access will raise average living standards of the children who are born. On the other hand, negative selection would result if, for instance, the most disadvantaged women are constrained in their abortion access, either geographically or financially. In this case, the living circumstances of the marginal child would be more advantageous than those of the average child, and abortion legalization may reduce the living standards of those children who are born."
} 
first year of life. ${ }^{7}$

From this it may be seen that there is a first-order, inverse relationship between abortion and crime and that there is a precedent for the mechanisms used by Donohue and Levitt to explain this relationship. In the remainder of this section, I shall examine these mechanisms in more detail. I shall begin with cohort size. After that, I shall turn to selection effects. The particular selection effects on which I shall focus are: wantedness, birthweight, race, single parenthood, age, socioeconomic status and education.

B.

Cohort Size. Donohue and Levitt note that legalization of abortion in the United States "is associated with roughly a 5 percent drop in birth rates." ${ }^{8}$ All else being equal, a drop in birth rates would lead to a drop in cohort size. A smaller cohort size then could lead to a subsequent drop in crime rates in one of two ways. First, the size of the cohort might impact its quality. For example, if a reduction in cohort size leads to smaller class sizes in schools, then teachers might be able to devote more time and energy to each individual student. Increased investment on the part of teachers and others might reduce

${ }^{7}$ Ibidem, p. 265.

8 John Donohue and Steven Levitt, "The impact of legalized abortion on crime," ibid., p. 386. In Freakonomics, this number is given as 6\%: “...the legalization of abortion had myriad consequences...births actually fell by 6 percent..." (Steven Levitt and Stephen Dubner, Freakonomics (New York: Harper Collins, 2005), p. 127). No source is given for this number in Freakonomics. 
the chances that a child will engage in criminal activity later in life. ${ }^{9}$ Second, even if reducing cohort size does not reduce the chances that a child will engage in criminal activity later in life, provided it does not increase these chances, "[w]hen those smaller cohorts reach the high-crime late adolescent years, there are simply fewer people to

${ }^{9}$ Donohue and Levitt hint at this hypothesis in a discussion of how long it should take for the reductions in crime from legalized abortion to manifest: "[i]f women who already had children in 1973 used abortion to prevent increases in family size, then abortion may indirectly lower criminality for the remaining children who will receive greater per child contributions of family resources" (John Donohue and Steven Levitt, "The impact of legalized abortion on crime," ibid., 393n19). The way in which cohort size might impact cohort quality is discussed under the rubric of "crowding effects" in more detail in Cristian Pop-Eleches, “The Impact of an Abortion Ban on Socioeconomic Outcomes of Children: Evidence from Romania,” Journal of Political Economy 114.4 (2006): 744-73, especially p. 747: “...if the fertility impact of the ban on abortions is large, one could imagine a negative crowding effect resulting form a larger cohort competing for scarce resources.” See also Theodore Joyce, Robert Kaestner and Sanders Korenman, "The effect of pregnancy intention on child development," Demography 37.1 (Feb., 2000): 83-94, especially p. 85, and Gary Becker and H. Gregg Lewis, “On the Interaction between the Quantity and Quality of Children," Journal of Political Economy 81.2 (Mar.Apr., 1973): S279-88. 
commit crime." $" 10$

Note that for this argument to hold, two things must be true. First, cohort sizes would have to begin to decrease in the 1970s and, in particular, around 1973. This is because the Donohue-Levitt hypothesis is not supposed to be merely a counterfactual, predictive hypothesis: the Donohue-Levitt hypothesis is supposed to be an explanatory hypothesis. In particular, it is supposed to explain why crimes steadily dropped beginning around 1991. If it does so through cohort size, then it follows that post-legal-abortion cohorts must be smaller than pre-legal-abortion cohorts.

Second, this reduction in cohort size must be due to abortion. For example, if it could be established that cohort sizes were smaller but that this was due solely to emigration, then it is difficult to see how the connection between reduced crime and abortion could be mediated by the mechanism of reduced cohort size. This is why Donohue and Levitt are careful to point out that legalization of abortion is associated with a drop in birth rate.

Now I would like to make two points in response to this argument. First, the 5 percent drop is estimated by comparing fertility rates between states that varied in the

${ }^{10}$ John Donohue and Steven Levitt, "The impact of legalized abortion on crime," ibid., p. 386. They argue that this is the "simplest way in which legalized abortion reduces crime" (ibid.). It is worth pointing out that this second version of the cohort size mechanism could work even if reducing cohort size in some way increased criminogenic propensities (e.g., through a sort of "converse crowding effect" if added time and energy investment from adults were in some way smothering). 
timing of abortion legalization. ${ }^{11}$ However, natality data from Vital Statistics of the United States 1979 indicate a more nuanced story. ${ }^{12}$ Registered births decreased by 3.7\% in 1973 when abortion was legalized nationwide. However, they then increased by $0.7 \%$ in 1974; decreased by $0.5 \%$ in 1975; and after that steadily increased until 1979. In 1979 there were 3,494,398 registered births, an increase of more than 200,000 over the 1972 numbers $(3,258,411)$. Birth rates follow a similar pattern: they decreased from 15.6 to

${ }^{11}$ Donohue and Levitt cite P. Levine, D. Staiger, T.J. Kane and D.J. Zimmerman, “Roe v. Wade and American Fertility," National Bureau of Economic Research Working Paper No. 5616, June 1996. The working paper has been published since that time: Phillip Levine, Douglas Staiger, Thomas Kane and David Zimmerman, "Roe v. Wade and American Fertility," American Journal of Public Health 89.2 (1999): 199-203. The sentence to which this footnote is appended is copied from the "Methods" from this paper. Levine et al. are careful to note that there are potentially confounding effects from more widely available contraceptives during this time period.

12 This point is made in Franklin Zimring, The Great American Crime Decline (Oxford:

Oxford University Press, 2006), pp. 93-4. 
14.9 in 1973 and then ended up climbing to 15.9 in $1979 .{ }^{13}$

I turn now to my second point: demographic data from the 1990s also militate against reduced cohort sizes as the mechanism underlying the connection between legalized abortion and crime reduction. In particular, resident population estimates by age from the United States Census Bureau indicate that the 14-17 year old cohort increased in size every year from July $1990(13,322,000)$ to November $2000(15,743,000)$; the $18-24$ year old cohort decreased by about 2 million from July $1990(26,835,000)$ to July 1996 $(24,843,000)$ and then increased steadily by almost the same amount by November 2000

${ }^{13}$ It might be wondered how to make sense of the fact that the number of registered births was increasing in tandem with the number of abortions. But as Joyce points out, legalizing abortion might lead to an increase in unwanted pregnancies (Ted Joyce, "Did Legalized Abortion Lower Crime?" ibid., p. 6). In Freakonomics it is pointed out that "conceptions rose by nearly 30\%" after abortion was legalized (Steven Levitt and Stephen Dubner, Freakonomics, ibid., p. 127. No source is given for this number in the endnotes). One hypothesis that would explain this increase in conceptions is that legal access to abortion leads people to be more irresponsible in their sexual behavior. The idea is that legalizing abortion decreases some of the risks associated with irresponsible sexual behavior and therefore decreases the incentive for avoiding such behavior. This hypothesis is bolstered by data from the CDC, which indicate that gonorrhea and syphilis incidences are significantly and positively correlated with abortion legalization (Jonathan Klick and Thomas Stratmann, "The effect of abortion legalization on the incidence of Sexually Transmitted Diseases," Law and Economics Working Paper Series 02-11). 
$(26,748,000)$.

It might be objected that had abortion not been legalized in 1973, there would have been more births in the 1970s and larger cohorts in the 1990s. On these grounds, one might think that the cohort size mechanism is not threatened by the data cited in the previous two paragraphs: crime would have been higher in the 1990s on account of the larger cohorts that would have been coming of age if abortion had not been legalized, and natality and demographic data are irrelevant. But this mistakes the nature of the Donohue-Levitt hypothesis. Again: the Donohue-Levitt hypothesis does not say merely counterfactually that crime would have been higher if abortion had not been legalized. The Donohue-Levitt hypothesis states that the actual decrease in crime observed in the 1990s after the 1991 crime peak was due in part to the legalization of abortion. Consider, for example, the following passage from the conclusion of their original paper:

The evidence we present is consistent with legalized abortion reducing crime rates with a twenty-year lag. Our results suggest that an increase of 100 abortions per 1000 live births reduces a cohort's crime by roughly 10 percent...These estimates suggest that legalized abortion is a primary explanation for the large drops in murder, property crime, and violent crime that our nation has experienced over the last decade. Indeed, legalized abortion may account for as much as one-half of the overall 


$$
\text { crime reduction. }{ }^{14}
$$

From this it may be seen that the data reproduced above is prima facie inconsistent with the Donohue-Levitt hypothesis if it rests on a cohort size mechanism. ${ }^{15}$ I turn now to selection effects. I begin with wantedness.

\section{C.}

Wantedness. The basic idea behind the wantedness mechanism is that legalized abortion leads to fewer unwanted babies being born. In their original paper, Donohue and Levitt argue that "[t]he impact of unwantedness is large because abortion rates of unwanted pregnancies are very high, whereas wanted pregnancies are by definition not aborted." ${ }^{16}$ In subsequent publications, Donohue and Levitt seem to suggest that this is

${ }^{14}$ John Donohue and Steven Levitt, "The impact of legalized abortion on crime," ibid., p. 414.

${ }^{15}$ Zimring makes a similar point (see Franklin Zimring, The Great American Crime Decline, ibid., p. 97).

${ }^{16}$ John Donohue and Steven Levitt, "The impact of legalized abortion on crime," ibid., p. 390. 
the main mechanism underlying the connection between abortion and crime reduction. ${ }^{17}$ The reason reducing unwanted pregnancies reduces crime is that unwanted babies are more likely to suffer abuse and neglect, and children who have suffered abuse and neglect are at an increased risk for criminal involvement later in life. To support this idea, Donohue and Levitt cite studies of European women who sought but were denied the right to have an abortion in jurisdictions where governmental approval was required: according to these studies, "these women overwhelmingly kept their babies, rather than giving them up for adoption, but...they often resented the unwanted children and were far less likely than other mothers to nurture, hold, and breastfeed these children." ${ }^{18}$ Levitt sums up the argument in an exchange in Slate:

${ }^{17}$ See, for example, John Donohue and Steven Levitt, "Further Evidence That Legalized Abortion Lowered Crime: A Reply to Joyce,” The Journal of Human Resources 39.1 (Winter, 2004): 29-49, especially p. 30: "Donohue and Levitt (2001) present five pieces of evidence consistent with the hypothesis that cohorts born after the legalization of abortion have lower crime rates because legalized abortion reduces the number of unwanted children, who are at higher risk of engaging in criminal conduct when they grow up."

18 John Donohue and Steven Levitt, "The impact of legalized abortion on crime," ibid., p. 388. These claims are also made in Freakonomics: after citing the same studies, Levitt and Dubner assert that "[r]esearchers found that in the instances where the woman was denied an abortion, she often resented her baby and failed to provide it with a good home" (Steven Levitt and Stephen Dubner, Freakonomics, ibid., p. 124). 
The theoretical justification for our argument rests on two simple assumptions: 1) Legalized abortion leads to fewer "unwanted" babies being born, and 2) unwanted babies are more likely to suffer abuse and neglect and are therefore at an increased risk for criminal involvement later in life. ${ }^{19}$

If there are fewer children who are at increased risk for criminal involvement later in life, then crime rates will decrease, so it follows that legalized abortion reduces crime rates.

I would like to examine, first, the connection between unwantedness and abuse and, second, the decrease in abuse and neglect that this argument requires. I shall say six things about the first and two things about the second. I shall begin by questioning the argument above.

${ }^{19}$ Steven Levitt and Steven Sailer, "Does Abortion Prevent Crime," Slate (Aug. 24, 1999). For a similar statement of the argument, see Steven Levitt, "Understanding Why Crime Fell in the 1990s: Four Factors That Explain the Decline and Six That Do Not," The Journal of Economic Perspectives 18.1 (Winter 2004): 163-90, especially pp. 181-2: "The underlying theory rests on two premises: 1) unwanted children are at greater risk for crime, and 2) legalized abortion leads to a reduction in the number of unwanted births." See also Steven Levitt and Stephen Dubner, Freakonomics, ibid., p. 127: "Legalized abortion led to less unwantedness; unwantedness leads to high crime; legalized abortion, therefore, led to less crime." 
First, Donohue and Levitt seem to use the wanted-unwanted distinction to track whether a woman desires to carry a pregnancy to term: in the quotation above, they claim that "wanted pregnancies are by definition not aborted." Similarly, in the Slate exchange quoted above, Levitt goes on to argue "...that abortion reduces the number of unwanted children, is true virtually by definition." But for one thing, a woman might be conflicted or not acting fully rationally when she decides to get an abortion. These decisions might be complicated. Finer notes that " $8 \%$ of pregnancies ending in abortion that women reported in the face-to-face interviews for the 2002 NSFG [National Survey of Family Growth] were described as intended." ${ }^{20}$ For another thing, a woman's desire to have a baby should not be confused with her desire to care for a baby to which she has given birth. A study of women whose applications for therapeutic abortions in Sweden in 1948 were denied found that $81 \%$ of those who gave birth reported being satisfied with the way things had turned out. ${ }^{21}$ A more realistic psychology (allowing for phenomena like adaptive preference formation) might make more tenuous the connection between not being able to get a desired abortion and abuse and neglect.

${ }^{20}$ Lawrence Finer and Stanley Henshaw, "Disparities in Rates of Unintended Pregnancy in the United States, 1994 and 2001," Perspectives on Sexual and Reproductive Health 38.2 (Jun., 2006): 90-6, at 91.

${ }^{21}$ Kerstin Hock, "Refused Abortion. A Follow-Up Study of 249 Women Whose Applications Were Refused by the National Board of Health in Sweden," Acta Psychiatrica Scandinavica Supplementum 38.S168: 7-156. The conclusions are summarized on pages 123-31. 
Second, as noted by Donohue and Levitt, the studies they cite to support the wantedness mechanism focus on women whose abortion petitions were rejected. Some of the studies focus on women whose abortion petitions were rejected twice (for the same pregnancy). ${ }^{22}$ But filing for a petition seems like the kind of thing that would disturb the "system" under consideration in a nontrivial way: it might make one question whether the results from these studies generalize well to a pregnant woman who desires but is not allowed to get an abortion because the procedure is generally illegal. ${ }^{23}$ To corroborate this hesitancy at generalization, it might be noted that in a study comparing cohorts born immediately before and immediately after a ban on abortion took effect in Romania, it was found that the post-ban cohort attained more years of schooling and greater labor market success than the pre-ban cohort (despite being born only months apart). Post-ban

${ }^{22}$ For example, see Z. Matejcek, Z. Dytrych and V. Schuller, "The Prague study of children born from unwanted pregnancies," International Journal of Mental Health 7.3/4 (Fall-Winter, 1978/79): 63-77, which is one of the studies reviewed in Paul Dagg, "The Psychological Sequelae of Therapeutic Abortion-Denied and Completed," The American Journal of Psychiatry 148.5 (May, 1991): 578-85. Dagg's review article is cited in John Donohue and Steven Levitt, "The impact of legalized abortion on crime," ibid., p. 388 and Steven Levitt and Stephen Dubner, Freakonomics, ibid., p. 299. ${ }^{23}$ At the very least, the operational definition of wantedness used in these studies does not generalize to the connection of abortion and crime proposed by Donohue and Levitt. 
cohorts also had lower crime rates than pre-ban cohorts. ${ }^{24}$ I shall discuss this study in more detail below, but these results suggest that members of the post-ban cohort were not subject to greater levels of criminogenic abuse or neglect than the pre-ban cohort.

The third thing I would like to say also has to do with the petitions: the reason that women in these studies were required to submit petitions is that the jurisdictions in which they lived had made legal only therapeutic abortion. In the US, by way of contrast, Roe $v$. Wade legalized elective abortion. It is true that the women in these studies were denied therapeutic abortions. But if one assumes that these women would not have applied (in some cases twice) if they did not have some objective grounds for thinking that their petitions were reasonable, then, again, it becomes difficult to generalize any results about whether their children were abused or neglected to the children of women who would not have been able to get elective abortions in the US had Roe v. Wade not happened.

Fourth, overlooking the difficulties raised in the previous two paragraphs and with due respect to Donohue and Levitt (and Dubner), I contend that the results from these studies do not give strong support for the wantedness mechanism. Many of the studies find that "the ascertained differences [between wanted children and unwanted children] are not particularly dramatic or remarkable" 25 or that "[t]he unwanted children agreed

\footnotetext{
${ }^{24}$ Cristian Pop-Eleches, "The Impact of an Abortion Ban on Socioeconomic Outcomes of Children: Evidence from Romania," Journal of Political Economy, ibid.

${ }^{25}$ Z. Matejcek, Z. Dytrych and V. Schuller, “The Prague study of children born from unwanted pregnancies," ibid., p. 75.
} 
with the controls in most respects." ${ }^{26}$ A study that followed these children into their $30 \mathrm{~s}$ found that "the differences [between wanted and unwanted children] are no longer statistically significant with regard to registration for criminality, alcohol and drug abuse and neglect of children." ${ }^{27}$ Furthermore, these studies often hypothesize that observed differences are due to factors like living in a single parent household rather than increased rates of abuse or neglect. Thus, these studies might provide better evidence for the single parenthood mechanism (discussed below) than for the wantedness mechanism. Indeed, the study just mentioned that followed the children into their 30 s found that the differences between wanted and unwanted children were further attenuated when they controlled for family fixed effects by looking at the siblings of these children, suggesting that the differences between wanted and unwanted children were due to genetic or environmental differences that might not be immediately connected with wantedness. ${ }^{28}$

The fifth point I want to make concerns the direction of the causal relationship

${ }^{26}$ M. Hultin and J. O. Ottoson, "Perinatal conditions of unwanted children," Acta Psychiatrica Scandinavica 47.S221 (March, 1971): 59-76, at 69.

${ }^{27}$ L. Kubicka, Z Matejcek, HP David, Z Dytrych, WB Miller, Z Roth, “Children from unwanted pregnancies in Prague, Czech Republic revisited at age thirty," Acta Psychiatrica Scandinavica 91.6 (June, 1995): 361-9, at 367. ${ }^{28}$ L. Kubicka, Z Matejcek, HP David, Z Dytrych, WB Miller, Z Roth, “Children from unwanted pregnancies in Prague, Czech Republic revisited at age thirty," ibid., especially pp. 367-8. A similar point is made in Theodore J. Joyce, “Abortion and Crime: A review," ibid., p. 8. 
between abortion and subsequent abuse and/or neglect of children. A 1985 study of the mothers of 532 children reported to the Baltimore Department of Social Services as physically abused during the years $1975-7$ found that mothers in maltreating families were significantly more likely to have had a stillbirth or reported abortion or a prior child death. ${ }^{29}$ These findings were duplicated and expanded upon in later studies. ${ }^{30}$ The explanation offered by the authors of these later studies is that an abortion interferes with the parent-infant bonding process between a mother and children resulting from subsequent pregnancies. The authors argue that getting an abortion might lead a mother to engage in abusive and/or neglectful behavior with subsequent children. If this explanation is correct, then it poses a problem for the wantedness mechanism.

The sixth and final point I would like to make about the connection between unwantedness and abuse has two parts. The first has to do with the fact that a woman

${ }^{29}$ Mary Benedict, Roger White, Donald Cornely, "Maternal Perinatal Risk Factors and Child Abuse," Child Abuse and Neglect 9 (1985): 217-24.

${ }^{30}$ Philip Ney, Tak Fung, Adele Rose Wickett, "Relationship between induced abortion and Child Abuse and Neglect: Four studies," Pre- and Peri-natal Psychology Journal 8.1 (1993): 43-63. 
might get an abortion in order to delay rather than to avoid pregnancy. ${ }^{31}$ Recent studies of why women undergo abortion reveal that the most commonly cited "most important reason" is that the women are not ready for a(nother) child/that the timing is wrong ( $27 \%$ in 1987 and $25 \%$ in 2004). This suggests that these women might go on to have a fullterm pregnancy later. ${ }^{32}$ That this might have been happening in the 1970s is supported by the fact that fertility rates, which had been dropping continuously since 1957, remained steady after 1973. The second part of this is that a recent study of the effect of pregnancy

${ }^{31}$ Donohue and Levitt are careful to point this out. See John Donohue and Steven Levitt, "The impact of legalized abortion on crime," ibid., p. 381 or 386n9. See also John Donohue and Steven Levitt, "Further Evidence That Legalized Abortion Lowered Crime: A Reply to Joyce," ibid., p. 33: "As long as the number of unwanted births falls, even if total births do not decline at all, one would expect to see better life outcomes on average for the resulting cohorts." Note that if a woman gets an abortion in 1973 because she is not ready to have a baby and then subsequently carries a pregnancy to term a few years later, her lifetime fertility would not be decreased by the abortion. Thus, it is not the case that Donohue and Levitt have to demonstrate a "negative relationship between state abortion rates and state fertility rates" in order to demonstrate an increase in unwanted childbearing (pace Ted Joyce, "Further Tests of Abortion and Crime," NBER Working Paper No. 10564 (June, 2004), at 15).

${ }^{32}$ Lawrence Finer, Lori Frohwirth, Lindsay Dauphinee, Susheela Singh, Ann Moore, "Reasons U.S. Women Have Abortions: Quantitative and Qualitative Perspectives," Perspectives on Sexual and Reproductive Health 37.3 (2005): 110-8. 
intention on maternal behavior and child development found that there are no significant differences in maternal behaviors (such as breast feeding and heavy smoking) between mistimed and wanted pregnancies. ${ }^{33}$ The fact that mistimed pregnancies are not associated with adverse maternal behavior is problematic for the wantedness mechanism, for this mechanism hinges on the idea that if aborted pregnancies had been carried to term, they would be more likely than other children to be abused.

I now turn to the two points I want to make about the decrease in abuse and neglect required by the wantedness mechanism. First, according to the National Center on Child

\footnotetext{
${ }^{33}$ Theodore Joyce, Robert Kaestner and Sanders Korenman, "The effect of pregnancy intention on child development," ibid.. See also Theodore J. Joyce, “Abortion and Crime:
} A review," ibid., p. 7. This study is notable because it uses a multivariate analysis that controls for potentially confounding variables like the socioeconomic status of the mother. It also is notable because unlike some previous studies it distinguishes not only between intended and unintended pregnancies but also, within unintended pregnancies, between unwanted pregnancies and mistimed pregnancies. This distinction comes from the practice of demographers who divide unintended pregnancies into two categories: those where a woman wanted to become pregnant at some time in the future but not yet (mistimed), and those where a woman did not want to become pregnant now or in the future (unwanted) (see, for example, Lawrence Finer and Stanley Henshaw, "Disparities in Rates of Unintended Pregnancy in the United States, 1994 and 2001," Perspectives on Sexual and Reproductive Health 38.2 (June, 2006): 90-6, especially p. 91. See also Theodore J. Joyce, “Abortion and Crime: A review,” ibid., 5n7). 
Abuse and Neglect, between the first National Incidence Study (conducted in 1979-80) and the second (1986-87), countable cases of maltreatment increased by $66 \%$; the rate of physical abuse increased by $58 \%$; the rate of sexual abuse increased by $300 \%$; and the rate of moderate injury from maltreatment increased by $89 \%$. Moving from the second study to the third (conducted in 1993-96) there is a statistically significant increase in all categories of maltreatment in both the rates and the total numbers of children harmed. These data do not go back far enough to make comparisons between pre-Roe $v$. Wade and post-Roe v. Wade cohorts. However, they do go back far enough to pose a problem for the wantedness mechanism. Because the wantedness mechanism relies on increased rates of abortion ushering in decreasing rates of abuse or neglect as the stepping stone to decreasing rates of crime, it seems to presuppose both that child abuse in the 70 s would be lower than child abuse in the 60 s and that child abuse at the turn of the 70 s would be lower than that in the mid-80s: to explain a continuous decrease in crime in the 90 s and through the 2000s by means of the wantedness mechanism, there must be a corresponding decrease in abuse and neglect in the $80 \mathrm{~s}$ and $90 \mathrm{~s}$. Thus, these data suggest that the decrease in abuse and neglect required by the wantedness mechanism might not have taken place. In corroboration of this it might be noted that a study of reports to child protection agencies from January 1, 1965 to December 31, 1984 found a steady increase in child abuse during this 20 year time period. Although this study looks only at a single county in Indiana (unlike the National Incidence Studies), it is notable for two reasons: first, it enables comparison of pre-Roe v. Wade cohorts with post-Roe v. Wade cohorts; and second, the author tries to control for the changing definitions of child abuse during 
this time period. The study concludes that "[d]espite the expansion of the definition of child maltreatment that appears to be involved in these data, evidence points to a genuine increase in violence, molestation, or neglect of children." ${ }^{34}$ Again, this suggests that the decrease in abuse and neglect required by the wantedness mechanism did not take place.

The final point I shall make in this section concerns infant mortality. A study of US mortality data for children under 5 years of age shows that there is no statistically significant drop in the number of homicides of under 1 year old infants correlated with Roe v. Wade, and there has been a steady increase in the number of homicides of 1-4 year olds since at least $1960 .{ }^{35}$ The authors of the study conclude that the legalization of abortion is not associated with a sudden change in trends associated with homicides of children under 5 years of age. ${ }^{36}$ But if legalizing abortion leads to a decrease in unwanted babies and if a decrease in unwanted babies leads to a decrease in abuse and neglect, one

\footnotetext{
${ }^{34}$ Dean Knudson, "Child Maltreatment over Two Decades: Change or Continuity?"
} Violence and Victims 3.2 (1988): 129-144, at 143.

${ }^{35}$ The rate of increase of homicides of 1-4 year olds decreases slightly in 1975, but it is useful to recall the point made above about "early repeal" states: 1975 is (at least prima facie) too late for a change in homicides of 1-4 year olds to be attributable to legalized abortion. Zimring also discusses this point (see Franklin Zimring, The Great American Crime Decline, ibid., p. 92).

${ }^{36}$ Susan Sorenson, Douglas Wiebe and Richard Berk, "Legalized Abortion and the Homicide of Young Children: An Empirical Investigation," Analyses of Social Issues and Public Policy 2.1 (2002): 239-56. 
also might expect that a decrease in abortion would lead to a decrease in infant homicides. ${ }^{37}$

The fact that there is neither a decrease in abuse or neglect when post-Roe v. Wade cohorts are coming of age nor a decrease in infant homicides when these cohorts are infants seems to militate against the idea that legalized abortion ushered in a decrease in criminogenic abuse and neglect. Note that (as with the cohort mechanism) it will not suffice for the wantedness mechanism to say that rates of abuse and neglect would have been higher during these times if abortion had been illegal: to explain an actual decrease in crime by means of the wantedness mechanism, there must be an actual decrease in abuse or neglect. Based on the foregoing, it seems to me that the balance of evidence tells against (or at least does not tell in favor of) the wantedness mechanism. I now turn to an examination of other selection effects proposed by Donohue and Levitt.

\footnotetext{
${ }^{37}$ This connection is drawn in Susan Sorenson, Douglas Wiebe and Richard Berk, "Legalized Abortion and the Homicide of Young Children: An Empirical Investigation," ibid., p. 243: "One could logically assert that the homicides of infants might be reduced because they would be more likely to be born into a household in which they are wanted and in which resources are perceived to be adequate for their care." It is also notable that the factors that Sorenson et al. list as increasing the chances of a child being a homicide victim are the same as those listed by Donohue and Levitt as increasing the chances of a child growing up to become a criminal: "A young child is more likely to be a homicide victim if the mother is unmarried, a teenager, or has not graduated from high school" (ibid., p. 241).
} 
D.

Birthweight. In their original paper, Donohue and Levitt note that "[a] number of studies have shown that the availability of abortion improves infant outcomes by reducing the number of low birthweight babies and neonatal mortality." 38 In a follow-up article, they make a similar point and conclude that "if legalizing abortion has a positive effect on birth outcomes then...it should not be surprising that legalizing abortion would have a positive effect on life outcomes such as criminal activity as well." ${ }^{39}$ Birthweight also factors into a discussion of parenting in Freakonomics. ${ }^{40}$ In support of this, a study in the early 2000s found a correlation between low birthweight and higher rates of chronic conditions and of neurosensory impairment. The same study also shows that very low birthweight infants have significantly lower mean IQ scores and scores on various subtests of academic achievement than other infants. ${ }^{41}$

However, there are three points that should be made in response to this. First, the fact that neonatal mortality decreases when abortion is available seems like it should

${ }^{38}$ John Donohue and Steven Levitt, "The impact of legalized abortion on crime," ibid., p. 387, see also p. 414.

39 John Donohue and Steven Levitt, "Further Evidence That Legalized Abortion Lowered Crime: A Reply to Joyce," ibid., p. 38.

${ }^{40}$ Steven Levitt and Stephen Dubner, Freakonomics, ibid., chapter 5.

${ }^{41}$ Maureen Hack, Daniel Flannery, Mark Schluchter, Lydia Cartar, Elaine Borawski, Nancy Klein, "Outcomes in Young Adulthood for Very-Low-Birth-Weight Infants," New England Journal of Medicine 346 (2002): 149-57. 
discount (rather than favorably augment) the cohort size and other mechanisms proposed by Donohue and Levitt. Second, a more recent study (than those cited by Donohue and Levitt) that controls for family background finds relatively weak support for the hypothesis that unintended pregnancy is associated with poor infant health. ${ }^{42}$ Third and finally, when it comes to criminal activity, which is what is of interest for the DonohueLevitt hypothesis, the study from the early 2000s cited above shows that there are no significant differences between the very low birthweight group and the normal birthweight group in the rates of conviction for a crime or incarceration in jail or juvenile detention. In fact, fewer very low birthweight men than male controls had ever had contact with the police, and the very low birthweight participants reported significantly lower rates of alcohol and marijuana use than the controls. ${ }^{43}$ This militates against the birthweight mechanism.

E.

Race. The race mechanism begins by noting that blacks account for a disproportionate amount of criminal activity. For example, according to data released by the FBI, $49.74 \%$ of arrests for murder and non-negligent manslaughter in 2011 were black. But in that same year, according to the US census bureau, blacks made up only $13.1 \%$ of the population. However, blacks also account for a disproportionate number of

\footnotetext{
${ }^{42}$ Theodore J. Joyce, Robert Kaestner and Sanders Korenman, “The Effect of Pregnancy Intention on Child Development," Demography 37.1 (Feb., 2000): 83-94.

${ }^{43}$ Maureen Hack, Daniel Flannery, Mark Schluchter, Lydia Cartar, Elaine Borawski, Nancy Klein, "Outcomes in Young Adulthood for Very-Low-Birth-Weight Infants," ibid.
} 
abortions. For example, in 1994, 30\% of all abortions in the US were given to black women. This meant that the rate of abortions for black women was 54 (per 1000 women of reproductive age) in 1994, the highest rate based on race in that year. (White women had a rate of 16 that year.) Moreover, 1994 was not an anomalous year in that regard: in $2000,31.7 \%$ of all abortions in the US were given to black women. The rate of abortions for black women that year was 49 , again the highest rate based on race. (In the same year, the rate of abortions for white women was 13.$)^{44}$ Donohue and Levitt explain this as follows:

Fertility declines for black women are three times greater than for whites...Given that homicide rates of black youths are roughly nine times higher than those of white youths, racial differences in the fertility effects of abortion are likely to translate into greater homicide reductions. ${ }^{45}$

\footnotetext{
${ }^{44}$ Rachel Jones, Jacqueline Darroch and Stanley Henshaw, "Patterns in the socioeconomic characteristics of women obtaining abortions in 2000-2001," Perspectives on Sexual and Reproductive Health 34.5 (2002): 226-35 and Rachel K. Jones and Megan Kavanaugh, "Changes in Abortion Rates Between 2000 and 2008 and Lifetime Incidence of Abortion," American Journal of Obstetrics and Gynecology 117.6 (2011): 1358-66. ${ }^{45}$ John Donohue and Steven Levitt, "The impact of legalized abortion on crime," ibid., p. 390.
} 
Race is sometimes taken as a proxy for socioeconomic status in this context. ${ }^{46}$ But there could be something else going on. For example, there could be systematic bias in the penal system against blacks. For that reason, I follow Donohue and Levitt in treating the race mechanism separately from the socioeconomic mechanism. There are at least two points worth making about the race mechanism.

First, according to Vital Statistics data, the percent of births to black women has increased steadily since at least 1960: in 1960, approximately $14 \%$ of registered births were to black women; in 1970, that number was $15.3 \%$; in 1974 it was $16.0 \%$; and by 1979 it was $16.5 \%{ }^{47}$ Second and similarly, according to US Census data, blacks have increased continuously in both absolute numbers and as a percent of the population since 1930. In 1970 , there were 22.6 million blacks (11.1\% of the population); by 1990 , that number had climbed to 30 million (12.1\% of the population). ${ }^{48}$ This should be unsurprising because birth rates for black women remained consistently higher than those for white women during the 1970s. But it does raise a problem for the race mechanism: Donohue and Levitt are arguing that abortion leads to a lower percentage of blacks in the population and this (perhaps by appeal to socioeconomics, perhaps bias, perhaps something else) explains the decrease in crime; this argument looks difficult to maintain

${ }^{46}$ See, for example, Franklin Zimring, The Great American Crime Decline, ibid., p. 95. ${ }^{47}$ Zimring makes a similar point (Franklin Zimring, The Great American Crime Decline, ibid., pp. 94-5).

48 "We the Americans: Blacks," U.S. Department of Commerce, Economics and Statistics Administration, Bureau of the Census, Issued September 1993. 
in light of the fact that the percentage of blacks actually increased. ${ }^{49}$

F.

Single Parenthood. The single parenthood mechanism begins by noting that unmarried women get more abortions than married women. For example, in 2000 married women accounted for only $17 \%$ of abortions. In that same year, women who were unmarried and were not cohabiting with their partners accounted for $57.5 \%$ of abortions. In 2008 , married women accounted for only $14.8 \%$ of abortions; in that same year, women who were unmarried and were not cohabiting accounted for $56 \%$ of abortions. ${ }^{50}$ But growing up in a single parent household makes it more likely that a child will engage in crime. Therefore, by decreasing the percentage of children growing up in single parent households, legalizing abortion decreases crime. Donohue and Levitt explain the single parenthood mechanism together with the age mechanism (which I shall discuss separately below):

Teenagers and unwed women experience reductions in fertility of 13 and 7

${ }^{49}$ Levitt seems to be aware of this: in a 2004 publication he states that "between 1990 and 2000, the black population rose from 12.1 percent to 12.9 percent" (Steven Levitt, "Understanding Why Crime Fell in the 1990s: Four Factors That Explain the Decline and Six That Do Not," ibid., p. 171). It is unclear whether he realizes that this poses a problem for the race mechanism.

${ }^{50}$ Rachel K. Jones, Lawrence B. Finer and Susheela Singh, Characteristics of U.S. Abortion Patients, 2008, New York: Guttmacher Institute, 2010. 
percent, respectively, well above that for non-teenage, married women. Rasanen et al. [1999] find, after controlling for other characteristics, that having a teenage mother roughly doubles a child's propensity to commit crime, as does growing up with a single parent. Accounting for these two factors raises the estimated impact of abortion on homicide from 8.9 percent to 12.5 percent. $^{51}$

The single parenthood mechanism also is appealed to in Freakonomics. ${ }^{52}$ Levitt and Dubner then propose a way in which the crime reduction benefits from the single parenthood mechanism and the age mechanism are compounded through time: the aborted baby boys of single, teenage mothers will not grow up to commit crimes, and the aborted baby girls of single, teenage mothers will not grow up to become single, teenage mothers who will give birth to more future criminals:

And the post-Roe cohort was not only missing thousands of young male criminals but also thousands of single, teenage mothers - for many of the

${ }^{51}$ John Donohue and Steven Levitt, “The impact of legalized abortion on crime," ibid., p. 390.

52 Steven Levitt and Stephen Dubner, Freakonomics, ibid., pp. 126-127: "One study has shown that the typical child who went unborn in the earliest years of legalized abortion would have been...60 percent more likely to grow up with just one parent...Growing up in a single-parent home roughly doubles a child's propensity to commit crime." 
aborted baby girls would have been the children most likely to replicate their own mothers' tendencies..$^{53}$

I shall return to this idea for "compound" crime reduction in my discussion of the age mechanism (below). For now, I shall focus on the single parenthood mechanism.

The basic objection that I have for the single parenthood mechanism is that the percent of children growing up in single parent households increased during the relevant time frame. ${ }^{54}$ According to Vital Statistics of the United States 1979, the number of births to unmarried women increased every year from 1948 until 1979; the birth rate for unmarried women increased from 24.5 in 1973 to 27.8 in 1979; and the rate of divorce increased from 4.3 in 1973 to 5.3 in $1979 .{ }^{55}$ Zimring shows that there has been an uninterrupted rise in the percentage of total births to single mothers between 1965 and 1980. ${ }^{56}$ There are various explanations for this phenomenon. For example, it might be argued that on the one side, women who were against abortion and/or contraceptives had an incentive to engage in sexual activity lest they be at a competitive disadvantage to other women whereas on the other side, men had less incentive to take responsibility for

\footnotetext{
${ }^{53}$ Steven Levitt and Stephen Dubner, Freakonomics, ibid., p. 129. ${ }^{54}$ See also James Wilson, “Dismal Science,” Commentary 120.1 (Jul/Aug, 2005): 67-9, especially p. 68.

${ }^{55}$ See also Philip Cook and John Laub, “After the Epidemic: Recent Trends in Youth Violence in the United States," Crime and Justice 29 (2002): 1-37, especially p. 21. ${ }^{56}$ Franklin Zimring, The Great American Crime Decline, ibid., p. 94 figure 4.3.
} 
pregnancies because legalizing abortion meant that having a baby became the physical choice of a woman. ${ }^{57}$ By positing a causal connection between legalized abortion and the increased percent of single parent households during this time period, this explanation inverts the single parenthood mechanism. But regardless of the explanation, the single parenthood mechanism is difficult to maintain in light of the increase in single parent households..$^{58}$

\section{G.}

57 This explanation is explored in George A. Akerlof, Janet L. Yellen and Michael L. Katz, "An Analysis of Out-of-Wedlock Childbearing in the United States," The Quarterly Journal of Economics 111.2 (1996): 277-317.

${ }^{58}$ Lott and Whitley make the point more forcibly: "From the 1960s through to the late 1980s (the last years in which births could have any effect on crime rates during the 1990s), there has been a tremendous increase in the rate of out-of-wedlock births. On average during $1965-69$, only $4.8 \%$ of whites were born out of wedlock, rising to $16.1 \%$ 20 years later (1985 to 1989). For blacks, the numbers rose from $34.9 \%$ to $61.8 \% \ldots$ [furthermore] unmarried women used to be much more likely to put up their children for adoption. In 1969 only about $28 \%$ of children born out of wedlock were being raised by mothers who were still unmarried within three years. By 1984, that same fraction doubled to $56 \%$. Hence, before legalized abortion most of the children born out of wedlock ended up in families with a father" (John Lott and John Whitley, “Abortion and Crime: Unwanted Children and Out-of-Wedlock Births,” Economic Inquiry 45.2 (Apr., 2007): 304-24, at 305). 
Age. The age mechanism is similar to the single parenthood mechanism and the version of it offered by Donohue and Levitt was reproduced above: legalizing abortion decreases teenage motherhood which decreases later criminality. However, there is a key difference between these two mechanisms: whereas the percentage of single parent households increased during the relevant time frame, there are various pieces of evidence that militate in favor of the age mechanism. For one thing, mean age of mother was 24.4 in 1973 and rose to 27.2 by 2000 , an increase of 2.8 years. ${ }^{59}$ Similarly, the $15-19$ birth rate decreased from 61.7 in 1973 to 51.5 in 1978 and remained in the low 50s into the 1980s. ${ }^{60}$ Finally, the percent of births to women $\leq 19$ years old decreased steadily from $1973(19.7 \%)$ to $1987(12.4 \%)^{61}$

The objection I would like to press against the age mechanism is that teenagers who would be willing to get an abortion might be relevantly different from teenagers who

${ }^{59}$ It is notable that it rose incrementally every year during that time period: there was no decrease at all. See "Mean Age of Mother, 1970-2000," National Vital Statistics Reports 51.1 (Dec. 11, 2002), table 1.

${ }^{60}$ It increased to 53 in 1980 before decreasing back to 50.2 in 1986 . The decrease between 1980 and 1986 was not as steady as the decrease from 1973 to 1978 . See "Births: Final Data for 2013," National Vital Statistics Reports 64.1 (Jan. 15, 2015), table 4. ${ }^{61} \mathrm{~L}$ Lu, Y Chong, BE Hamilton, SC Curtin, JA Martin, B Tejada-Vera and PD Sutton, Natality trends in the United States, 1909-2013, National Center for Health Statistics, 2015. 
would not be willing to get an abortion. ${ }^{62}$ Thus, although Donohue and Levitt might be right that the child of a teenager who is unwilling to get an abortion is at higher risk of becoming a criminal, it might be the case that the child of a teenager who would be willing to get an abortion would not be at higher risk of becoming a criminal. In an early study of teens in Ventura County, California between 1972 and 1974, researchers demonstrated that pregnant teens with better grades, more completed schooling and not on public assistance were much more likely to abort than their poorer, less academically oriented counterparts. ${ }^{63}$ Along the same lines, another study, this one based on data from the National Health and Social Life Survey (NHSLS) and the National Longitudinal Survey of Youth (NLSY), found that teens who abort are similar along observed characteristics to teens who were never pregnant, and both of these groups differ significantly from pregnant teens who spontaneously abort or carry to term. ${ }^{64}$ These selection effects are not limited to teenagers. A study including older women found that

${ }^{62}$ This point is made originally in Ted Joyce, "Did legalized abortion lower crime?" ibid., p. 26.

${ }^{63}$ Arleen Leibowitz, Marvin Eisen and Winston Chow, “An Economic Model of Teenage Pregnancy Decision-Making," Demography 23.1 (1986): 67-77. Joyce cites this article in Ted Joyce, "Did legalized abortion lower crime?" ibid., p. 26.

${ }^{64}$ V. Hotz, Susan McElroy and Seth Sanders, "Teenage Childbearing and Its Life Cycle Consequences: Exploiting a Natural Experiment," The Journal of Human Resources 40.3 (2005): 683-715. Joyce cites an earlier, unpublished version of this article in Ted Joyce, “Did legalized abortion lower crime?" ibid., p. 26. 
unmarried women who abort have more completed schooling than their counterparts who carry the pregnancy to term. ${ }^{65}$ However, the point is that these selection effects pose a problem for the age mechanism; the reason for citing the fact that the selection effects are found also among older women is to make more plausible the fact that they are found among younger women. ${ }^{66}$ Additional corroboration of these selection effects can be found in the fact that although the percentage of teenage births decreased during this time

${ }^{65}$ Eve Powell-Griner and Katherine Trent, "Sociodemographic Determinants of Abortion in the United States," Demography 24.4 (1987): 553-61. This study is cited in Ted Joyce, “Did legalized abortion lower crime?” ibid., p. 26. In support of this point he also cites Janet Currie, Lucia Nixon and Nancy Cole, "Restrictions on medicaid funding of abortion," Journal of Human Resources 31.1 (1995): 159-88.

${ }^{66}$ Donohue and Levitt object that these studies give the conditional probability that a teenager will seek an abortion given that she has an unwanted pregnancy (John Donohue III and Steven Levitt, "Further Evidence That Legalized Abortion Lowered Crime: A Reply to Joyce," ibid., p. 38). But this objection seems incorrect: these studies seem to give the conditional probability that a teenager has certain characteristics given that she has sought an abortion. 
period, the percentage of single teenage births increased. ${ }^{67}$ In 1970, approximately $30 \%$ of live births to women under the age of 20 were outside marriage; by 1984 , approximately $56 \%$ of such births were so. ${ }^{68}$ This fact also seems to undermine the "compound" crime reduction mechanism discussed above, which would require a decrease in single teenage mothers. ${ }^{69}$ If the objection I am pressing is based on a correct

${ }^{67}$ Joyce argues that Zimring "uses national trends in fertility by age, race and martial status to show that there has been a seemingly uninterrupted rise in the percent of births to unmarried women and teens between 1965 and 1980" (Theodore J. Joyce, "Abortion and Crime: A review," ibid., 24n23). There is a subtle but important misunderstanding here. Zimring shows that there is an uninterrupted rise in the percent of births to unmarried women and in the percent of births to unmarried teens during this time period. However, Zimring does not show that there has been an uninterrupted rise in the percent of total births to teens (simpliciter) (Franklin Zimring, The Great American Crime Decline, ibid., p. 94 figure 4.3).

${ }^{68}$ Elizabeth C. Cooksey, "Factors in the Resolution of Adolescent Premarital Pregnancies," Demography 27.2 (May, 1990): 207-18, at 207. ${ }^{69}$ Cooksey finds a more direct problem for this mechanism: "Family structure is a significant predictor only for the white sample [Cooksey has three samples: whites, blacks and Hispanics], for which the main effect of coming from a nonintact family is to enhance the likelihood of out-of-wedlock childbearing" (Elizabeth C. Cooksey, "Factors in the Resolution of Adolescent Premarital Pregnancies," ibid., p. 213). This suggests that the compounding will be seen in at most one demographic. 
interpretation of the facts, then the problem for the age mechanism is that there is an added layer of selection: children of teenage mothers willing to get abortions are a special subgroup that does not conform to the generalization that children of teenage mothers are at higher risk of becoming criminals.

H.

Socioeconomic Status. The socioeconomic mechanism begins by noting that criminologists and economists have argued for a long time that there is a link between crime and, in particular, homicide and poverty. ${ }^{70}$ However, women below the poverty line

${ }^{70}$ See, e.g., Colin Loftin and Robert Hill, "Regional subculture and homicide," American Sociological Review 39.7 (1974): 14-24; Victor Flango and Edgar Sherbenou, "Poverty, urbanization, and crime," Criminology 14 (1976): 331-46; Robert Parker and M. Smith, "Deterrence, poverty, and type of homicide," American Journal of Sociology 85 (1979): 614-24; M. Dwayne and Robert Parker, "Type of homicide and variation in regional rates," Social Forces 59 (1980): 136-47; or Kirk Williams, "Sources of Homicide: Reestimating the Effects of Poverty and Inequality," American Sociological Review 49.2 (1984): 283-9. 
account for a disproportionate number of legal abortions. ${ }^{71}$ For example, in 1994, 25.5\% of all abortions in the US were given to women from families below the federal poverty line. This meant that the rate of abortions for such women was 36 (per 1000 women of reproductive age) that year, the highest rate based on income level. (Women from

${ }^{71}$ Levitt and Dubner argue that this was not the case for pre-Roe $v$. Wade illegal abortions: "Before Roe v. Wade, it was predominantly the daughters of middle- or upperclass families who could arrange and afford a safe illegal abortion. Now, instead of an illegal procedure that might cost $\$ 500$, any woman could easily obtain an abortion, often for less than $\$ 100$. What sort of woman was most likely to take advantage of Roe $v$. Wade? Very often she was unmarried or in her teens or poor, and sometimes all three" (Steven Levitt and Stephen Dubner, Freakonomics, ibid., p. 126). However, they do not seem to have any evidence that middle- and upper-class women accounted for a disproportionate number of pre-Roe $v$. Wade illegal abortions, and they also do not cite any sources for the premises underlying this argument. It is therefore perhaps worth pointing out that in the study gestured at in the main text above (and discussed in more detail below) comparing cohorts born immediately before and immediately after an abortion ban took effect in Romania, it was found that urban, educated women were more likely to have a legal abortion (i.e., prior to the ban) than their poorer counterparts (Cristian Pop-Eleches, “The Impact of an Abortion Ban on Socioeconomic Outcomes of Children: Evidence from Romania," Journal of Political Economy, ibid.). This suggests that the reality of abortion decisions might be more complicated than the cost-benefit analysis proposed here by Levitt and Dubner. 
families above $300 \%$ of the federal poverty line had a rate of 16 that year.) In 2000 , $26.6 \%$ of all abortions in the US were given to women from families below the federal poverty line, and the rate was 44 , again the highest rate based on income level. (In 2000 women from families above $300 \%$ of the federal poverty line had a rate of 10.$)^{72} \mathrm{By}$ 2008 , women from families below the federal poverty level accounted for $42.4 \%$ of all abortions. Their rate was 52.2. Abortion rates for other groups decreased during that time. ${ }^{73}$ Therefore (the socioeconomic mechanism concludes) legalized abortion leads to more women whose children have high probability of involvement in criminal activity

${ }^{72}$ Rachel Jones, Jacqueline Darroch and Stanley Henshaw, "Patterns in the socioeconomic characteristics of women obtaining abortions in 2000-2001," Perspectives on Sexual and Reproductive Health 34.5 (2002): 226-35 and Rachel K. Jones and Megan Kavanaugh, "Changes in Abortion Rates Between 2000 and 2008 and Lifetime Incidence of Abortion," American Journal of Obstetrics and Gynecology 117.6 (2011): 1358-66.

${ }^{73}$ Rachel K. Jones and Megan Kavanaugh, "Changes in Abortion Rates Between 2000 and 2008 and Lifetime Incidence of Abortion," ibid. 
getting abortions. ${ }^{74}$

The problem for the socioeconomic mechanism is that although childhood poverty does seem to have decreased in the 1960 s, it does not seem to have decreased in the

${ }^{74}$ Donohue and Levitt explain the socioeconomic mechanism in conjunction with the age mechanism and the single parenthood mechanism: “...women who have abortions are those most at risk to give birth to children who would engage in criminal activity. Teenagers, unmarried women, and the economically disadvantaged are all substantially more likely to seek abortions [Levine et al. 1996]. Recent studies have found children born to these mothers to be at higher risk for committing crime in adolescence [Comanor and Phillips 1999]" (John Donohue and Steven Levitt, "The impact of legalized abortion on crime," ibid., p. 381). Levitt and Dubner also group these three mechanisms together: "...the millions of women most likely to have an abortion in the wake of Roe v. Wadepoor, unmarried, and teenage mothers for whom illegal abortions had been too expensive or too hard to get - were often models of adversity. They were the very women whose children, if born, would have been much more likely than average to become criminals. But because of Roe v. Wade, these children weren't being born. This powerful cause would have a drastic, distant effect: years later, just as these unborn children would have entered their criminal primes, the rate of crime began to plummet" (Steven Levitt and Stephen Dubner, Freakonomics, ibid., p. 4). 
1970s or in the 1980s. In fact, it might have increased. ${ }^{75}$ According to the US Census Historical Poverty Tables, the percent of related children under 18 years below poverty increased from $15.1 \%$ in 1969 to $16.0 \%$ in 1979 and to $17.9 \%$ in $1989 .{ }^{76}$ Similarly, the percent of families with related children under 18 years below poverty increased from $11.8 \%$ in 1969 to $13.2 \%$ in 1979 to $14.9 \%$ in $1989 .{ }^{77}$ A recent study published by the Carsey School of Public Policy found that although the percent of children in low income families (family income is $200 \%$ of the federal poverty line) has decreased slightly since 1970 , the percent of children in poor families (family income is $100 \%$ of the federal poverty line) or in deep poverty (family income is $50 \%$ of the federal poverty line) has remained roughly constant or slightly increased since 1970 . The study also found that mean family incomes of families with children in all three of the three lowest income quintiles have remained steady or slightly decreased since 1970 (in adjusted 2014

\footnotetext{
${ }^{75}$ This is not to say that legalizing abortion did not enable some women in poverty to terminate their pregnancies. Perhaps childhood poverty levels would have been higher in the 1970s and 1980s if abortion had not been legalized. But as with the other mechanisms discussed above, to explain an actual decrease in crime in the 1990s by means of the socioeconomic mechanism (as Donohue and Levitt are committed to doing), there needs to have been an actual decrease in childhood poverty. ${ }^{76}$ CPH-L-169, "Related children under 18 years, by poverty status in 1969, 1979, 1989, and 1999 by state."

${ }^{77}$ CPH-L-174, "Families with related children under 18 years, by poverty status in 1969 , 1979, 1989, and 1999 by state."
} 
dollars). The authors summarize their findings as follows: "Overall, across the past fifty years [the study ends in 2013], the nation witnessed rapid declines in poverty during the 1960s, then a period of relative stability."78 This militates against the socioeconomic mechanism. ${ }^{79}$

I.

Education. The final selection mechanism I shall consider is education. Donohue and Levitt only gesture at this mechanism in their original paper. ${ }^{80}$ The mechanism is

${ }^{78}$ Beth Mattingly, Andrew Schaefer, Douglas Gagnon and Sarah Leonard, "Gaps in Youth Opportunity by State National," University of New Hampshire, Carsey School of Public Policy, Carsey Research (March 10, 2015).

${ }^{79}$ While arguing that the strong economy of the 1990 s did not contribute much to the decrease in crime during the 1990 s, Levitt concludes that there is a "weak link between macroeconomics and crime" (Steven Levitt, "Understanding Why Crime Fell in the 1990s: Four Factors That Explain the Decline and Six That Do Not," ibid., especially p. 171). Levitt might be right about this. But it undermines the socioeconomic mechanism, which relies on a strong link between macroeconomics and crime that manifests with a 20 year time lag, and in undermining this mechanism, this claim undermines the DonohueLevitt hypothesis (for which Levitt argues in the same article). It is unclear whether Levitt realizes this.

${ }^{80}$ See especially John Donohue and Steven Levitt, "The impact of legalized abortion on crime," ibid., p. 391. 
endorsed more explicitly in Freakonomics. ${ }^{81}$ The basic idea seems to hinge on two claims. First, low maternal education is a powerful criminogenic factor. Second, low maternal education is one of the factors driving women to get abortions after Roe $v$. Wade. ${ }^{82}$ Based on this, it may be concluded that legalizing abortion, by enabling women to attain higher levels of education, decreased their potential for raising criminals and ultimately decreased crime. I would like to make two points about this.

First, although it is true that maternal education seems to have increased during this time period, it seems unlikely to me that this is due to the legalization of abortion. For one thing, Vital Statistics reports from this period reveal that the percent of children born to women who had completed more than 12 years of schooling began to increase prior to 1973. For another thing, many men's colleges began to go coed and attitudes were changing about women's education around this time period. For these reasons, increasing levels of maternal education seem to me to be the result of a historical process that began before Roe v. Wade. In support of this it might be noted that at least according to recent studies, "would interfere with education" is not cited by many women as the most

${ }^{81}$ See especially Steven Levitt and Stephen Dubner, Freakonomics, ibid., p. 127.

${ }^{82}$ Donohue and Levitt also note that "[p]rior to the legalization of abortion, there was a very strong link between the number of unwanted births and low maternal education over the period from 1965 through 1970" (John Donohue and Steven Levitt, "The impact of legalized abortion on crime," ibid., p. 387). 
important reason for having an abortion. ${ }^{83}$ Low maternal education might not be as strong a driving factor in seeking abortions as Levitt and Dubner contend.

Second, a recent study finds that the percentage of children living in single-parent families in which the parent does not have a college degree has grown steadily since 1960 (through the 1970s and the 1980s) and at a much higher rate than the percentage of children living in single-parent families in which the parent had completed a bachelor's or more ${ }^{84}$ This might be due to selection effects like those noted above in the discussion of the age mechanism. As pointed out there, a study including older women found that unmarried women who abort have more completed schooling than their counterparts who carry the pregnancy to term. Similarly, another study finds that the effect of parental education on whether a pregnant teenage daughter will seek an abortion "is particularly strong and is pervasive regardless of race/ethnicity." 85 That is, teenage daughters whose

${ }^{83}$ In $1987,10 \%$ of women cited "would interfere with education or career plans" as the most important reason for having an abortion, which suggests that the percent who would cite "would interfere with education" would be lower. In 2004, 4\% of women cited this reason. These numbers are taken from Lawrence Finer, Lori Frohwirth, Lindsay Dauphinee, Susheela Singh, Ann Moore, "Reasons U.S. Women Have Abortions: Quantitative and Qualitative Perspectives," ibid., table 3.

${ }^{84}$ Beth Mattingly, Andrew Schaefer, Douglas Gagnon and Sarah Leonard, "Gaps in Youth Opportunity by State National," ibid.

${ }^{85}$ Elizabeth C. Cooksey, "Factors in the Resolution of Adolescent Premarital Pregnancies," ibid., p. 216. 
parents have a high level of education seem to be more prone to seek abortion ("the probability of having one in a family with the highest level of parental education is more than 2.5 times the probability found if neither parent completed high school"). ${ }^{86}$ Finally, as noted above, in the Romania study (which will be discussed in more detail shortly) it was found that urban, educated women were more likely to have a legal abortion than their poorer counterparts. ${ }^{87}$ But whether the growth noted in the first sentence of this paragraph is due to selection effects or something else is less important for current purposes: the point is that the percentage of children in a high risk group relevant to the education mechanism (single parent household with low parent education) was growing rather than shrinking during the relevant time period. This presents a problem for the education mechanism.

$\mathrm{J}$.

Concluding Remarks about the Mechanisms. From this it may be seen that many of the independent causal mechanisms through which abortion is supposed to reduce crime actually give evidence that crime should have increased in the 1990s. Cohort sizes increased rather than decreased; the percent of single parents increased rather than decreased; etc. Indeed, the predictions about crime increasing in the 1990s discussed

\footnotetext{
${ }^{86}$ Elizabeth C. Cooksey, "Factors in the Resolution of Adolescent Premarital Pregnancies," ibid., p. 216.

${ }^{87}$ Cristian Pop-Eleches, "The Impact of an Abortion Ban on Socioeconomic Outcomes of Children: Evidence from Romania," ibid.
} 
above were based in part on these mechanisms ${ }^{88}$ However, Donohue and Levitt concentrate their energies on explaining the different correlations that suggest a causal relationship rather than on the mechanisms through which this causal relationship works. So I turn to an examination of these correlations now.

III.

${ }^{88}$ In an article published one year before the original Donohue-Levitt hypothesis article, Blumenstein writes, "[t]he decline [in crime] after 1980 was significantly affected by the shrinking size of the cohorts in the high-crime ages, but the United States in the late 1990s was in a period of growing cohort sizes in the late teens and early twenties...Thus, if teenage age-specific crime rates were to remain constant, then the aggregate crime rate would increase as a result of the larger cohort sizes. This possibility spurred the warnings of a demographic 'crime bomb' set to go off during the 1990s" (Alfred Blumenstein, "Disaggregating the Violence Trends," in Alfred Blumenstein and Joel Wallman (ed.'s) The Crime Drop in America (Cambridge: Cambridge University Press, 2000): 13-44, at 28). Levitt and Dubner do seem to be aware of the warnings about this demographic "crime bomb" (see, e.g., Steven Levitt and Stephen Dubner, Freakonomics, ibid., p. 123; see also Steven Levitt, "Understanding Why Crime Fell in the 1990s: Four Factors That Explain the Decline and Six That Do Not," ibid., especially pp. 169-70). It is unclear whether they realize that the warnings undermine some of the mechanisms to which they appeal: if, e.g., someone predicts increased crime at time $t_{2}$ because cohort sizes at time $t_{1}$ are increasing, then explaining the counter-predictive decrease in crime at time $t_{2}$ through something that caused cohort sizes at time $t_{1}$ to decrease is problematic. 
A.

The Correlations. I shall divide up my discussion of the correlations into three subsections: international evidence; nation-level evidence; and state-level evidence. The international evidence subsection will focus on evidence from other countries (primarily Romania, Australia, Canada and the UK). The nation-level evidence subsection will focus on aggregate data from the US. The state-level evidence subsection will disaggregate data by state.

B.

International Evidence. In Freakonomics, Levitt and Dubner claim that "studies of Australia and Canada have...established a similar link between legalized abortion and crime" as that proposed in the Donohue-Levitt hypothesis. ${ }^{89}$ They also discuss the abortion ban in Romania:

Compared to Romanian children born just a year earlier, the cohort of children born after the abortion ban would do worse in every measurable way: they would test lower in school, they would have less success in the labor market, and they would also prove much more likely to become criminals. ${ }^{90}$

In a blog post defending the Donohue-Levitt hypothesis, Levitt lists the following as one

${ }^{89}$ Steven Levitt and Stephen Dubner, Freakonomics, ibid., p. 129.

90 Steven Levitt and Stephen Dubner, Freakonomics, ibid., p. 106. 
of the "basic facts that support the Donohue-Levitt hypothesis": "The evidence from Canada, Australia, and Romania also support the hypothesis that abortion reduces crime." 91 I shall begin by saying something about the evidence from each of the countries mentioned here starting with Romania. Then I shall say something about the UK before concluding with some remarks about other countries.

There are three things that should be noted about the results from the Romania study. The first is that, as noted by Levitt and Dubner, the author of the study finds that when he controls for maternal background, children born after the abortion ban had worse educational and labor market achievements as adults than children born before the ban. ${ }^{92}$ However, Levitt and Dubner do not mention that these results are conditional on controlling for maternal background. This leads to the second thing that should be noted about the result from the Romania study: when maternal background is not controlled for in this way, the author notes that "children born after the abortion ban attained more years of schooling and greater labor market success" than children born before the abortion ban. ${ }^{93}$ The author also points out that "urban, educated women were more likely to have abortions prior to the policy change, and the relative number of children born to this type

${ }^{91}$ Steven Levitt, http://www.freakonomics.com/2005/05/15/abortion-and-crime-whoshould-you-believe/.

${ }^{92}$ Cristian Pop-Eleches, "The Impact of an Abortion Ban on Socioeconomic Outcomes of Children: Evidence from Romania," ibid., p. 744.

${ }^{93}$ Cristian Pop-Eleches, "The Impact of an Abortion Ban on Socioeconomic Outcomes of Children: Evidence from Romania," ibid., p. 744. 
of woman increased after the ban." ${ }^{94}$ But the Donohue-Levitt hypothesis is about aggregate results for the cohort rather than results for subsets of the population. So the fact that aggregate outcomes were better is a problem. ${ }^{95}$

However, educational and labor market achievements are not the primary concern for the Donohue-Levitt hypothesis, and this leads to the third and last thing that should be noted about the Romania study, which concerns the criminal activity of post-ban cohorts. The crime rate comparisons in the Romania study are different from the comparisons of schooling and labor market success. For crime rate comparisons, the author uses penal case data, which gives information about the year of birth of the persons involved (but does not allow for disaggregation based on socioeconomic status), to construct crime rates for cohorts born between 1935 and 1985 . He finds that the crime rates for cohorts born in the three years after the ban (1967-69) were lower than those of previous cohorts. The author hypothesizes that "[t]he negative coefficient for the 1967-69 cohort suggests that the compositional changes [i.e., in the mothers carrying their pregnancies to term]

${ }^{94}$ Cristian Pop-Eleches, "The Impact of an Abortion Ban on Socioeconomic Outcomes of Children: Evidence from Romania," ibid., p. 744.

${ }^{95}$ It is also perhaps worth noting that Pop-Eleches had data for and thus could control for maternal background only in approximately $50 \%$ of the cases (see Cristian Pop-Eleches, "The Impact of an Abortion Ban on Socioeconomic Outcomes of Children: Evidence from Romania," ibid., p. 751). So the result about controlling for maternal background is more limited than the general result about the increased educational and labor market success of the cohort. 
have the strongest effect on crime behavior, just as in the education and labor regressions." 96

From this it may be seen that the Romania study does seem to show that abortion legislation can have an impact on the quality of a cohort by means of selection effects. But it does not do so in the direction required by the Donohue-Levitt hypothesis. Instead of impacting primarily uneducated women, the ban impacted primarily urban, educated women. Instead of resulting in a less successful cohort or higher crime rates because its members were subject to a criminogenic environment (e.g., abuse and resentment), the post-ban cohort as a whole was more successful and had a lower crime rate than the preban cohort. I turn now to the Australia study. ${ }^{97}$

${ }^{96}$ Cristian Pop-Eleches, “The Impact of an Abortion Ban on Socioeconomic Outcomes of Children: Evidence from Romania," ibid., pp. 768-9. Levitt and Dubner, in reporting that the post-ban cohort "would also prove much more likely to become criminals," seem to be referring to the 1970 cohort, which had a higher rate of criminal activity than the preban cohorts. However, given the large gap in time between the 1970 cohort and the 1966 cohort and given everything that was happening in Romania over the relevant time span (manifested in the Romanian revolution in 1989), this might be the result of historical contingency.

${ }^{97}$ Joyce is critical of Levitt and Dubner for calling this piece a study: "the article is little more than speculation as to a possible association that includes little data and no analysis” (Theodore J. Joyce, “Abortion and Crime: A review,” ibid., p. 39. A similar claim can be found on p. 47). 
Leigh and Wolfers focus on homicide in Australia. ${ }^{98}$ They provide two main pieces of evidence in favor of a connection between homicide rates and abortion in Australia. First, the Australian homicide rate reached a peak of 2.4 (per 100,000 people) in 1988. Thereafter it declined, remaining below 2 for the 1990s. There was no single decision in Australia like Roe v. Wade (or like the Romanian abortion ban). But this was about 20 years after a number of different decisions made abortion more readily available in Australia in the late 1960s and early 1970s.$^{99}$ Second, Leigh and Wolfers provide some reason to believe that the areas in which abortion was legalized first experienced drops in their crime rates first:

Victoria, which legalised abortion in 1969, saw homicide decline from 1987-88. NSW [New South Whales], where it was legalised in 1971, saw homicide decline from 1989-90. The Northern Territory legalised abortion in 1974 and saw homicide decline from 1990-91. By contrast, Western Australia, where the legal status of abortion remained unclear until

${ }^{98}$ They explain their reasons for this on p. 29 (Andrew Leigh and Justin Wolfers, “Abortion and Crime," AQ: Australian Quarterly 72.4 (Aug.-Sep., 2000): 28-30, 40). It is perhaps worth pointing out that according to Leigh and Wolfers, although abortion rates increased in Australia after it was legalized, birth rates remained roughly constant (just as in the US). They suggest that in Australia women used abortion primarily for timing purposes (ibid., especially p. 29). ${ }^{99}$ Andrew Leigh and Justin Wolfers, “Abortion and Crime," ibid., p. 29. 
recently, has not seen any significant drop in its homicide rate. ${ }^{100}$

However, there are two points that should be made about this. First, Leigh and Wolfers admit that the evidence in favor of their second point is ambiguous: "the evidence for other regions does not support this proposition [i.e., the proposition that states where abortion was legalized first experienced drops in their crime rates first]. At best we can say that this part of the theory holds for the states where most Australians live." ${ }^{101}$ Second, the crime data cited by Leigh and Wolfers (i.e., the drop in the national homicide rate and the various regional homicide declines) actually might militate against the Donohue-Levitt hypothesis (pace Leigh, Wolfers, Donohue, Levitt and Dubner). Although the time-lag for the drop is suggestive, given that abortion rates increased in Australia after it was legalized (as in the US), the Donohue-Levitt hypothesis predicts that there would have been a small but prolonged decrease in crime rates. For example, writing in 2001 (roughly ten years after the Donohue-Levitt-hypothesis-abortiongenerated-crime-drops supposedly began), Donohue and Levitt claim that "legalized abortion will account for persistent declines of 1 percent a year in crime over the next two decades." ${ }^{102}$ This amounts to approximately 30 years of steady crime reduction. By way of contrast, the crime drops in Australia, although perhaps appreciable, seem to be limited

\footnotetext{
${ }^{100}$ Andrew Leigh and Justin Wolfers, “Abortion and Crime," ibid., p. 30.

${ }^{101}$ Andrew Leigh and Justin Wolfers, “Abortion and Crime," ibid., p. 30.

102 John Donohue and Steven Levitt, "The impact of legalized abortion on crime," ibid., p. 415.
} 
to an approximately two-year time span. Thus, it seems to me that the evidence from Australia is equivocal. ${ }^{103}$ I turn now to the Canada study.

Therapeutic abortion was legalized in Canada in 1969: to receive an abortion, a woman would have to demonstrate in a petition that her life or health was in danger. ${ }^{104}$ In 1988, the Canadian Supreme Court struck down the existing abortion law effectively legalizing elective abortion. ${ }^{105}$ In his study, Sen finds that general and teen abortion rates in the 1970s "are negatively and significantly correlated with trends in violent crime" in the 1990s. ${ }^{106}$ Further checks confirm the robustness of this relationship and Sen concludes that legalized abortion is responsible for approximately half of the $10 \%$ drop in

103 To be fair to Leigh and Wolfers, they do not take themselves to have established a conclusive link between abortion and crime in Australia. ${ }^{104}$ Anindya Sen, "Does Increased Abortion Lead to Lower Crime? Evaluating the Relationship between Crime, Abortion, and Fertility," The B.E. Journal of Economic Analysis and Policy 7.1 (2007, Article 48): 1-36, especially p. 5. ${ }^{105}$ Anindya Sen, "Does Increased Abortion Lead to Lower Crime? Evaluating the Relationship between Crime, Abortion, and Fertility," ibid., 5n13. ${ }^{106}$ Anindya Sen, "Does Increased Abortion Lead to Lower Crime? Evaluating the Relationship between Crime, Abortion, and Fertility," ibid., p. 20. 
violent crime in Canada in the 1990s. ${ }^{107}$ However, there are two things that should be said about this study.

First, as noted already in the discussion of the wantedness mechanism, therapeutic abortion is relevantly different from elective abortion. Thus, caution must be exercised

${ }^{107}$ Anindya Sen, "Does Increased Abortion Lead to Lower Crime? Evaluating the Relationship between Crime, Abortion, and Fertility,” ibid., p. 17. Sen's analysis leads him to conclude that in Canada, legalizing abortion decreased crime by means of the age mechanism. In particular, Sen tries to show this by correlating post-1969 teen fertility rates with crime rates in the 1990s (see especially p. 32: "OLS estimates suggest that the corresponding decline in teenage fertility was responsible for more than half the decline in violent crime over the specific time period"). Joyce points out that the model Sen uses in this analysis has problems. When Joyce uses his preferred model, his results suggest legalized abortion increased teen fertility in Canada (Theodore J. Joyce, "Abortion and Crime: A review," ibid., pp. 43-5). Joyce concludes from this that Sen's study is "a step backwards in the debate" because it fails to demonstrate an association between abortion legalization and teen fertility, "a seemingly necessary condition for an association between abortion and crime" (Theodore J. Joyce, "Abortion and Crime: A review," ibid., p. 45). However, I think that Joyce might be putting too much emphasis on teen fertility rates. As I understand it, fertility rates are used by Sen primarily to suggest a mechanism whereby legalized abortion decreases crime. While I agree with Joyce that there are problems with Sen's support for this mechanism, I do not think it is the only possible mechanism. 
when generalizing results from a system in which only therapeutic abortion is legal to a system in which elective abortion is legal (and vice versa). ${ }^{108}$ Second, Sen concedes that there is no correlation between abortion and property crime, ${ }^{109}$ and when he divides violent crime into homicide, robbery, sexual assault and physical assault, he finds that

${ }^{108}$ Sen tries to counter this point as follows: "a good deal of evidence suggests the difficulty in obtaining an abortion in Canada was quite low in most metropolitan areas by the time of complete U.S. legalization in nineteen seventy-three. Specifically, abortion applications in hospitals in most major cities were rarely denied. As well, there was a significant proliferation of private clinics offering similar services over the same time period. Finally, even if there were any problems in obtaining an abortion "close to home", there was always the option of crossing the border into the United States" (Anindya Sen, "Does Increased Abortion Lead to Lower Crime? Evaluating the Relationship between Crime, Abortion, and Fertility,” ibid., pp. 6-7). Sen might be right: obtaining an abortion in metropolitan areas in Canada might have been easy by 1973. But I find his evidence unconvincing. The fact that applications are rarely denied does not entail that they are being rubber-stamped: it is equally consistent with strict enforcement and women applying only when they have good reason. Moreover, abortion rates in Canada in the 1970s and the 1980s are substantially lower (in some years by a multiplicative factor of more than 1.5) than those in the US (as reported by Sen, ibid., p. 8). ${ }^{109}$ Anindya Sen, "Does Increased Abortion Lead to Lower Crime? Evaluating the Relationship between Crime, Abortion, and Fertility," ibid., p. 4: "abortion rates are insignificantly correlated with trends in property crimes." 
abortion is positively correlated with the first two and negatively correlated with the second two. ${ }^{110}$ This suggests to me that Sen's correlation is not tracking a causal

${ }^{110}$ Anindya Sen, "Does Increased Abortion Lead to Lower Crime? Evaluating the Relationship between Crime, Abortion, and Fertility," ibid., pp. 29-31. 
relationship of the kind required for the Donohue-Levitt hypothesis. ${ }^{111}$ I turn now to the UK study.

In 1968, abortion was decriminalized in England, Scotland and Wales under the

${ }^{111}$ Sen suggests a theory to explain why the correlation does not hold for property crime: he argues that the age mechanism and the birthweight mechanism predispose children to violent rather than to property crime (Anindya Sen, "Does Increased Abortion Lead to Lower Crime? Evaluating the Relationship between Crime, Abortion, and Fertility," ibid., pp. 25-6). However, there are at least four things that should be said about this. First, as Sen admits, the evidence for his theory is "merely suggestive" (Anindya Sen, "Does Increased Abortion Lead to Lower Crime? Evaluating the Relationship between Crime, Abortion, and Fertility," ibid., pp. 26). Second, as will be seen below, the results from the UK study are flipped: in the UK, violent crime is positively correlated with abortion and property crime is negatively correlated with abortion. Third, as also will be seen below, Donohue and Levitt appeal to correlations between abortion and both property crime and violent crime. Indeed, in a blog post defending the Donohue-Levitt hypothesis, Levitt lists the following as one of the "basic facts that support the Donohue-Levitt hypothesis": "Five states legalized abortion three years before Roe v. Wade. Crime started falling three years earlier in these states, with property crime (done by younger people) falling before violent crime" (Steven Levitt, http://www.freakonomics.com/2005/05/15/abortion-andcrime-who-should-you-believe/). Fourth and finally, Sen's theory does not seem to be able to sustain his finding that abortion is negatively correlated only with two kinds of violent crime and positively correlated with the other two. 
condition that two doctors state in good faith that continuation of the pregnancy would involve greater risk of injury to the physical or mental health of the pregnant woman or any of her existing children than carrying the pregnancy to term. ${ }^{112}$ Kahane et al. present a number of pieces of evidence that militate against a connection between abortion and crime in the UK during this time. I shall summarize what I take to be the eight most important.

First, although property crime did begin to decline in the 1990s, its decline did not begin until 1992: this is prima facie too big of a gap in time (24 years compared to the 18 year gap in the US) to support a connection with abortion. ${ }^{113}$ Second, "[v]iolent crime... increased more or less consistently over the whole period." 114 Third, plotting "cautions plus guilty" data based on cohorts, they note that the 16-20 age cohort and the 21 plus age cohort seem to follow a similar pattern (rather than a lagged decrease with the younger age cohort decreasing first as one would expect if abortion cause a decrease in crime). ${ }^{115}$

${ }^{112}$ I am simplifying for the sake of brevity the account given in Leo H. Kahane, David Paton and Rob Simmons, “The Abortion-Crime Link: Evidence from England and Wales," Economica 75.297 (Feb., 2008): 1-21, especially pp. 3-4.

${ }^{113}$ Leo H. Kahane, David Paton and Rob Simmons, "The Abortion-Crime Link: Evidence from England and Wales," ibid., pp. 5-6.

${ }^{114}$ Leo H. Kahane, David Paton and Rob Simmons, "The Abortion-Crime Link: Evidence from England and Wales," ibid., p. 6.

${ }^{115}$ Leo H. Kahane, David Paton and Rob Simmons, "The Abortion-Crime Link: Evidence from England and Wales," ibid., p. 6. 
Fourth, comparing England/Wales and Scotland crime rates with Northern Ireland and Republic of Ireland crime rates, the former do not decrease relative to the latter in the 1980s or the 1990s (in fact, the former seem to increase relative to the latter). But abortion remained illegal in Northern Ireland and in the Republic of Ireland during this time period, so if abortion had crime-reducing effects, one would expect to see these effects in the England/Wales and Scotland crime rates but not in the Northern Ireland or Republic of Ireland crime rates. ${ }^{116}$ Fifth, turning to a multivariate regression like that used by Donohue and Levitt (discussed below), it may be seen that in the UK, although property crime rates are negatively correlated with effective abortion rates, violent crime rates are positively correlated with effective abortion rates. Both correlations are statistically significant at the $1 \%$ level. ${ }^{117}$ Sixth, although total crime rates are negatively correlated with effective abortion rates, the model shows that the impact of abortion on crime in the UK is more than twice that in the US, which is prima facie implausible given that the abortion rate in the UK is consistently lower than that in the US. ${ }^{118}$ Seventh, this correlation does not withstand various robustness checks. For example, when London is removed from the data, the correlation between abortion and crime is not statistically

${ }^{116}$ Leo H. Kahane, David Paton and Rob Simmons, "The Abortion-Crime Link: Evidence from England and Wales," ibid., p. 8.

${ }^{117}$ Leo H. Kahane, David Paton and Rob Simmons, "The Abortion-Crime Link: Evidence from England and Wales," ibid., p. 12.

${ }^{118}$ Leo H. Kahane, David Paton and Rob Simmons, "The Abortion-Crime Link: Evidence from England and Wales," ibid., p. 13. 
significant. ${ }^{119}$ Eighth and finally, when age-specific analysis is performed (i.e., looking at crime rates for specific cohorts rather than aggregate crime rates) the correlations between offending rates and abortion rates become positive (but, to be fair, not always statistically significant). ${ }^{120}$

From this it may be seen that there are a number of prima facie contradictions in a Donohue-Levitt story from the international evidence. In the UK, abortion legalization is correlated with decreased property crime but increased violent crime; in Canada, it is correlated with decreased violent crime but not decreased property crime. In Canada, abortion legalization is correlated with increased homicide; in Australia it is correlated with decreased homicide. Finally, in Romania, an abortion ban is correlated with improved educational and labor market outcomes and decreased crime. In light of this, it is perhaps useful to note that in a recent study in which homicide data are plotted from 20 countries that have legalized or substantially liberalized abortion, it is found that although several countries (e.g., Canada, France and Italy) are consistent with the Donohue-Levitt hypothesis, many show the opposite correlation: an increase in crime 20 years after

${ }^{119}$ Leo H. Kahane, David Paton and Rob Simmons, "The Abortion-Crime Link: Evidence from England and Wales," ibid., pp. 13-4.

${ }^{120}$ Leo H. Kahane, David Paton and Rob Simmons, "The Abortion-Crime Link: Evidence from England and Wales," ibid., pp. 15-7. I shall return to the importance of age-specific analysis in the next subsection. However, it might be worth noting now that neither Sen nor Leigh and Wolfers were able to provide such analysis. 
abortion (e.g., Denmark, Finland, Hungary and Poland). ${ }^{121}$ Overlooking issues related to the difference between therapeutic and elective abortion, it seems to me that the international evidence is not conclusively in favor of the Donohue-Levitt hypothesis: if this is one of the "basic facts" in its support, then there might be grounds for doubt. I turn now to aggregate (nation-level) data from the US.

C.

Nation-Level Evidence. The main nation-level evidence in favor of the DonohueLevitt hypothesis comes from five characteristics of the crime drop in the 1990s: it was widespread, large, abrupt and persistent, and it began when the cohorts first exposed to legal abortion decisions in utero were entering their high-crime years. ${ }^{122}$ These characteristics offer disconfirmation of competing explanations and confirmation of the Donohue-Levitt hypothesis. For example, many cities did not improve their police forces but nonetheless saw large crime declines, so improving police forces cannot account for the widespread crime drop in the 1990s. ${ }^{123}$ By way of contrast, Roe v. Wade legalized abortion nationwide. Similarly, the rise in police numbers and increasing scale of imprisonment had been ongoing for more than a decade, so neither of these can explain

${ }^{121}$ Angela Dills, Jeffrey Miron and Garret Summers, "What do economists know about crime?", ibid., p. 16.

122 John Donohue and Steven Levitt, "The impact of legalized abortion on crime," ibid., p. 380.

${ }^{123}$ John Donohue and Steven Levitt, "The impact of legalized abortion on crime," ibid., p. 380 . 
the abrupt beginning to the crime drop or its timing. Again by way of contrast, Roe $v$. Wade legalized abortion in a single decision, and (again) there is consistency with the timing of legalizing of abortion and the subsequent drop in crime: "the peak ages in crime are roughly 18-24, and crime starts turning down around 1992, roughly the time at which the first cohort born following Roe v. Wade would hit its criminal prime." ${ }^{24}$ Moreover, seven years after Roe v. Wade, more than 1.6 million abortions were being performed annually: thus, the Donohue-Levitt hypothesis is consistent with the size of the crime drop and with its persistence. ${ }^{125}$ However, there are at least three pieces of nation-level evidence that militate against the Donohue-Level hypothesis.

First, disaggregating homicide data by age reveals that there are two crime declines in the 1990s. Homicide rates of older cohorts $(25-34,35-49)$ begin to decrease in the

\footnotetext{
${ }^{124}$ John Donohue and Steven Levitt, "The impact of legalized abortion on crime," ibid., p. 382.

125 John Donohue and Steven Levitt, "The impact of legalized abortion on crime," ibid., p. 380.
} 
early 1990s. Homicide rates of younger cohorts begin to decrease in the late 1990s. ${ }^{126}$ One way to see this is by noting that the average age of homicide offenders in the US decreased steadily from the mid-1980s until it reached a minimum in $1994 .{ }^{127}$ Among the younger cohorts, homicide rates of the 16-20 and 21-25 cohorts peak in 1993; the homicide rate of the $10-15$ cohort peaks in $1994 .{ }^{128}$ Robbery trends are similar: the peak for the $<20$ cohort is in $1994 .{ }^{129}$ Homicide and robbery are sometimes thought to be the most reliably measured crimes because the offenses are reasonably well defined and the definitions have been stable over time. ${ }^{130}$ I have focused on them here for that reason. But it is notable that when other kinds of crime are focused on, although the stories are more

${ }^{126}$ This point has been made by a number of researchers. See, for example, Alfred Blumenstein, "Disaggregating the Violence Trends," ibid.; James Wilson, "Dismal Science," ibid., p. 68; James Alan Fox, "Demographics and US Homicide," in Alfred Blumenstein and Joel Wallman (ed.'s) The Crime Drop in America (Cambridge: Cambridge University Press, 2000): 288-317, especially pp. 302-4; and Richard Rosenfeld, "The case of the unsolved crime decline," Scientific American (Feb., 2004): 82-9, especially pp. 86-7. Some, like Rosenfeld, seem to take it as decisive. 127 This point is made in John Lott and John Whitley, “Abortion and Crime: Unwanted Children and Out-of-Wedlock Births," ibid., 310n16.

128 John Lott and John Whitley, “Abortion and Crime: Unwanted Children and Out-ofWedlock Births," ibid., p. 310.

${ }^{129}$ Moreover, the decline in robbery is relatively short-lived, ending in 2000. Alfred Blumenstein, "Disaggregating the Violence Trends," ibid., p. 27. ${ }^{130}$ Alfred Blumenstein, "Disaggregating the Violence Trends," ibid., p. 19. 
complicated, they are nonetheless problematic for the Donohue-Levitt hypothesis. For example, juvenile aggravated assault rates, like robbery rates, peak in 1994. Juvenile simple assault rates increase until a peak in the late 1990s. Juvenile drug possession/use arrest rates increase sharply in the 1990s. Juvenile drug sale/manufacturing arrest rates increase to a peak in the second half of the 1990s. Etc. ${ }^{131}$ All of this presents two challenges: (1) it undermines the consistency of timing claim and (2) it undermines the explanation of the reductions because abortion induced crime reduction presumably would effect younger cohorts before effecting older cohorts.

A second but similar problem arises when homicide data are disaggregated by sex and race. ${ }^{132}$ Doing so reveals that the white female homicide rate fluctuates but remains roughly constant throughout the 1980s and the early 1990s for the 14-17 year old cohorts and the 18-24 year old cohorts. Moreover, the decreases in the homicide rates for these cohorts of white females in the late 1990s are inappreciable when compared to those associated with white or black males. Black female homicide trends show a steady decrease in all age groups beginning around 1991. Because abortion-reducing-crime effects presumably would manifest equally in both sexes (although perhaps not equally in both races: see the discussion of the race mechanism above) this presents a challenge for

131 The trends reported in the previous sentences are taken from Howard N. Snyder, “Arrest in the United States, 1990-2010," U.S. Department of Justice, Office of Justice Programs, Bureau of Justice Statistics, Patterns and trends (Oct., 2012), NCJ 239423. ${ }^{132}$ A similar point is made in John Lott and John Whitley, “Abortion and Crime: Unwanted Children and Out-of-Wedlock Births," ibid., p. 313. 
the Donohue-Levitt hypothesis. Again, although the stories are more complicated, disaggregating rates for other kinds of crime presents similar problems.

Third and finally, if the Donohue-Levitt hypothesis holds, then one might expect that (all else being equal) crime rates in the 2000s (more than 10 years after the crime reducing effects of abortion supposedly began to manifest) would be lower than crime rates in the 1950s (when abortion was illegal and before the pill and other birth control mechanisms became more widely available). However, that is not the case. The US homicide rate (per 100,000 capita) was in the $4 \mathrm{~s}$ in the 1950 s (e.g., 4.6 in 1950); it nearly doubled from the mid-1960s to the late 1970s, reaching a peak of 10.2 in 1980; and after remaining steady for some years, it has decreased to the $5 \mathrm{~s}$ in the 2000 s (e.g., 5.6 in 2005). The homicide rate in 2000 (5.5) was lower than it has been since 1965 (5.1) but considerably higher than it was when it reached a local minimum of 4.0 in $1957 .{ }^{133}$ Total crime rates, total violent crime rates and total property crime rates tell a similar although more complicated story. This might lead some to suspect that in focusing on the 1990s crime drop, Donohue and Levitt have mistaken the nature of the phenomenon that needs explaining: a steady increase followed by a steady decrease in crime rather than simply a steady decrease.

Donohue and Levitt might respond to these things. For example, they plausibly might argue that the magnitude of the effects they predict are so small on a yearly basis that they easily could be overwhelmed by other effects in a simple time-series analysis;

133 James Alan Fox and Marianne W. Zawitz, "Homicide trends in the United States," Bureau of Justice Statistics. 
that some of the trends reported above are artifacts of period effects or shifting policies; that trends from crimes other than homicide are not reliable; that crime-reduction effects of abortion should manifest more strongly in males than in females; ${ }^{134}$ that getting an abortion was very difficult in some states (notwithstanding Roe v. Wade), which renders dubious the interpretation of national trends in terms of abortion; and that all else is not equal in comparing homicide rates from the 1950s with homicide rates in the 2000s and therefore that such a comparison is not meaningful. However, in making these responses, Donohue and Levitt also would undercut the nation-level evidence that they cite in their favor. So on the whole, it seems to me that the balance of evidence from the nation-level goes against the Donohue-Levitt hypothesis.

D.

State-Level Evidence. There are two main kinds of state-level evidence that Donohue and Levitt cite in support of the Donohue-Levitt hypothesis: interstate analyses and intrastate analyses. The interstate analyses capitalize on two main differences between states: timing of abortion legalization and abortion rates. I shall begin with interstate timing and then interstate rates. After that I shall move to intrastate analysis before discussing some problems with these analyses.

There were five "early repeal" states (Alaska, California, Hawaii, New York and

${ }^{134}$ Some of the studies they cite of women whose abortion petitions were denied (discussed above) show that the effects of unwantedness manifest more strongly in males than females. See, for example, Z. Matejcek, Z. Dytrych and V. Schuller, "Children from unwanted pregnancies," Acta Psychiatrica Scandinavica 57.1 (Jan., 1978): 67-90. 
Washington) for which elective abortion was legal in 1970, three years before Roe $v$. Wade made it legal nation-wide. However, Donohue and Levitt point out that crime started falling three years earlier (in the 1982-5 period) in early repeal states than in other states. ${ }^{135}$ Moreover, the decline during this time period is in property crime rather than murder or violent crime, and property crime "is disproportionately done by the young."136 This confirms the Donohue-Levitt hypothesis in two ways: (1) the timing is consistent with abortion as an explanation for the crime drops and (2) it suggests that the crime drop began with younger cohorts, which is what one would expect if abortion is the root cause.

Concerning abortion rates, Donohue and Levitt divide the 50 states and the District of Columbia into three equal groups based on abortion frequency: high, medium and low. Then they examine violent crime rates, property crime rates and homicide rates for the $<25$ cohorts and the $>25$ cohorts in these states from 1985 to 1997 . With regard to the $<25$ cohorts, they find that the "high" abortion frequency category experiences the greatest decreases or smallest increases for all three categories of crime during this time period; the "low" category experiences the smallest decreases or greatest increases for all three categories of crime; and the "medium" category experiences medium decreases or

${ }^{135}$ See John Donohue and Steven Levitt, "The impact of legalized abortion on crime," ibid., p. 387, table I.

${ }^{136}$ John Donohue and Steven Levitt, "The impact of legalized abortion on crime," ibid., p. 394. 
increases. ${ }^{137}$ With regard to the $>25$ cohorts, they find that there is no consistent pattern. This confirms the Donohue-Levitt hypothesis in two ways: (1) it directly correlates abortion rates of the relevant age group with crime drops and (2) by showing that the crime rates for the $>25$ cohorts do not follow the same pattern as the $<25$ cohorts, it shows that the correlation cannot be explained merely by appeal to period effects if those period effects would act indiscriminately on old and young alike. Donohue and Levitt then confirm these correlations more rigorously using panel data regressions and using a multivariate model that includes controls for potentially confounding factors such as police per 1000 residents. They also run sensitivity checks such as excluding potentially outlier, very high abortion states. This shows that the interstate comparison based on abortion frequency is robust. ${ }^{138}$

Moving to the intrastate analysis, Donohue and Levitt use another multivariate model to link abortion rates in a particular state in a particular year with the crime committed by the cohort born in that year while controlling for potentially confounding interactions. ${ }^{139}$ They focus on the categories of violent crime and property crime and the

${ }^{137}$ See John Donohue and Steven Levitt, "The impact of legalized abortion on crime," ibid., p. 400, table II. See also John Donohue and Steven Levitt, "Further Evidence That Legalized Abortion Lowered Crime: A Reply to Joyce," ibid., pp. 31-2, figures 1 and 2. 138 John Donohue and Steven Levitt, "The impact of legalized abortion on crime," ibid., pp. 400-7.

${ }^{139}$ See John Donohue and Steven Levitt, "Further Evidence That Legalized Abortion Lowered Crime: A Reply to Joyce," ibid., p. 31. 
analysis covers the years from 1985 to 1996 . Homicide is dropped from the analysis because "[t]here are too few murder arrests per single age category per state." ${ }^{140}$ They find that higher abortion rates around the time a cohort is born are associated with lower arrest rates in their teens and twenties. ${ }^{141}$ This further confirms the Donohue-Levitt hypothesis because it shows that within a given state, the cohorts most effected by abortion go on to commit the least crime.

However, there are a number of problems with these analyses. I shall begin by mentioning a few that Donohue and Levitt have responded to. After explaining the responses, I shall discuss some problems that might not be soluble.

Foote and Goetz have shown that a coding error in the data used for the original paper resulted in the intrastate analysis being incorrect. ${ }^{142}$ Similarly, Joyce has leveled a suite of objections to the abortion data used in these analyses. For one thing, he notes that in their original article, Donohue and Levitt assume for the purposes of their statistical analysis that there were no abortions prior to legalization. Joyce points out that (1) this assumption is false (Kansas had an observed abortion ratio of 369 per 1,000 live births in

140 John Donohue and Steven Levitt, "The impact of legalized abortion on crime," ibid., p. 412.

141 John Donohue and Steven Levitt, "The impact of legalized abortion on crime," ibid., p. 412 and also p. 413, table VII.

${ }^{142}$ Christopher L. Foote and Christopher F. Goetz, "The Impact of Legalized Abortion on Crime: Comment," The Quarterly Journal of Economics 123.1 (Feb., 2008): 407-23, especially p. 410. 
1972 (in 1973, its ratio was 414 per 1,000 live births)) and (2) this false assumption introduces bias into their equation. ${ }^{143}$ For another thing, he prefers to use abortion data from the Center for Disease Control (CDC) and an algorithm used by the Alan Guttmacher Institute (AGI) for assigning abortions by state of residence to the raw AGI data used by Donohue and Levitt. ${ }^{144} \mathrm{He}$ also argues that abortion is not a good proxy for unwantedness and that to test for a link between abortion and crime, "[t]he abortion rate should be inversely related to fertility rates." 145

In response to Foote and Goetz, Donohue and Levitt have shown that the results from their intrastate analysis still stand once the coding error is corrected. ${ }^{146}$ In response to Joyce, Donohue and Levitt argue that the bias introduced by assuming there were no abortions prior to 1973 would undermine the correlation between abortion and crime: the fact that the correlation is still there despite the bias indicates its robustness. To demonstrate this, they show that if they estimate pre-1973 abortion rates by linear

${ }^{143}$ Ted Joyce, "Did Legalized Abortion Lower Crime?" The Journal of Human Resources 39.1 (Winter, 2004): 1-28, at 5-6.

${ }^{144}$ Ted Joyce, "Did Legalized Abortion Lower Crime?," ibid., section II.C, especially p. 5. ${ }^{145}$ Ted Joyce, “Abortion and Crime: A Review,” ibid., p. 38. 146 John J. Donohue and Steven D. Levitt, "Measurement Error, Legalized Abortion, and the Decline in Crime: A Response to Foote and Goetz," The Quarterly Journal of Economics 123.1 (Feb., 2008): 425-40, especially section II. 
backcasting, they get the same results. ${ }^{147}$ Furthermore, they show that using CDC data does not undermine their results. ${ }^{148}$ Finally, they note that most of their mechanisms (because they are selection mechanisms) do not require an inverse relationship between

${ }^{147}$ John Donohue and Steven Levitt, "Further Evidence That Legalized Abortion Lowered Crime: A Reply to Joyce," ibid., p. 36. In a more recent reply, Joyce argues that the original assumption of 0 abortions prior to legalization "implies that there was no variation in the wantedness of cohorts born between 1961 and 1973" (Theodore J. Joyce, "Abortion and Crime: A review," ibid., p. 26). Because there was variation among these cohorts, Joyce maintains that statistical analysis must be limited to cohorts for which data on abortion exists. However, I think Joyce might be putting too much confidence in these data, which are, at best, estimates.

148 John Donohue and Steven Levitt, "Further Evidence That Legalized Abortion Lowered Crime: A Reply to Joyce,” ibid., p. 37. In their most recent analysis, Donohue and Levitt use CDC data as a corrective for potential errors in AGI data (see John J. Donohue and Steven D. Levitt, "Measurement Error, Legalized Abortion, and the Decline in Crime: A Response to Foote and Goetz,” ibid., especially pp. 430-2). Joyce takes them to task for this because the two data series are not independent (Ted Joyce, "A Simple Test of Abortion and Crime," The Review of Economics and Statistics 91.1 (Feb., 2009): 112-23, especially section II.C). However, it is unclear whether correcting for this error will have a substantive impact on their results. 
abortion rates and fertility rates. ${ }^{149}$

But there are at least three problems with the analyses presented above that might not have answers that ultimately hold up. First, the interstate timing analysis is in tension with the intrastate analysis. Donohue and Levitt note that the intrastate analysis shows that the smallest impact of abortion appears to occur in the under 17 age range. ${ }^{150}$ But in the 1982-1985 period relied on for the interstate timing analysis, most of the early repeal cohorts would have been under 17 . Thus, if the intrastate analysis is held firm, it renders prima facie implausible the claim that the early drop in property crime (which falls by $8.3 \%$ ) in early repeal states is the result of abortion legalization.

Second, although the intrastate rate analysis is suggestive, Foote and Goetz point out that extending the analysis backward in time shows that there is a "pre-1985 relationship between abortion and crime." ${ }^{151}$ It is implausible that there was a causal relationship between abortion rates and crime rates prior to 1985 because the cohorts would have been too young (less than 12 years old in non-early repeal states). So this suggests that the correlation between abortion rates and crime rates after 1985 is spurious (or perhaps tracking an omitted variable that drives both abortion rates and crime rates).

149 John Donohue and Steven Levitt, "Further Evidence That Legalized Abortion Lowered Crime: A Reply to Joyce," ibid., p. 33.

150 John Donohue and Steven Levitt, "The impact of legalized abortion on crime," ibid., p. 412 and also p. 413, table VII.

${ }^{151}$ Christopher L. Foote and Christopher F. Goetz, “The Impact of Legalized Abortion on Crime: Comment," ibid., p. 416. 
Donohue and Levitt perform various additional tests that suggest that there is no omitted variable. ${ }^{152}$ But it is perhaps worth noting in this regard that when individual states are plotted to find a correlation between crime rates and abortion rates (rather than aggregated into three groups based on whether they are in the top, middle or lowest 17), there is no obvious relationship. ${ }^{153}$

Third and finally, Donohue and Levitt use arrest numbers rather than arrest rates in their intrastate analysis. ${ }^{154}$ This is a problem because Foote and Goetz point out that using arrest rates undermines the intrastate results. In response, Donohue and Levitt suggest that using arrest numbers as opposed to arrest rates can distinguish between cohort size and selection effect mechanisms. After redoing their analysis with this in mind, they find

${ }^{152}$ John J. Donohue and Steven D. Levitt, "Measurement Error, Legalized Abortion, and the Decline in Crime: A Response to Foote and Goetz," ibid., section V.

${ }^{153}$ Donohue and Levitt plot the \% change in violent crime rate, property crime rate and homicide rate vs. change in effective abortions in Figures IVa-c (John Donohue and Steven Levitt, "The impact of legalized abortion on crime," ibid., pp. 398-399). The $\mathrm{r}^{2}$ values range from 0.12 for murder to 0.45 for property crime (ibid., p. 400). ${ }^{154}$ In their original paper, Donohue and Levitt claim that they use arrest numbers because of "absence of reliable measures of state population by single year of age" (John Donohue and Steven Levitt, "The impact of legalized abortion on crime," ibid., p. 411). However, as noted by Foote and Goetz, "the Census Bureau constructs these population measures for each year beginning in 1980" (Christopher L. Foote and Christopher F. Goetz, “The Impact of Legalized Abortion on Crime: Comment," ibid., p. 410). 
that "at least $40 \%$ of the measured impact of abortion on arrests is operating through the selection channel." ${ }^{155}$ Subsequent studies have duplicated this result. For example, Ananat et al. note that "our results align with the previous literature in that reduced abortion costs led to reduced crime, but largely through a reduction in cohort size (total crime) rather than through selection (crime per capita)." ${ }^{156}$ But as pointed out in the first half of this paper, very little of the impact of abortion in the 1970s on arrests in the 1990s can be operating through the cohort size channel: cohort sizes were increasing rather than decreasing in the 1990s. This suggests that the correlation might not be tracking a causal mechanism. It is perhaps worth noting in this regard that if one looks at homicide rates for 16 year olds, 17 year olds, 18 year olds, 19 year olds and 20 year olds, in nonrepeal states or repeal states, it may be seen that they all follow a similar trend. In particular, they all climb rapidly after 1987 and decline rapidly after 1995. This seems to undermine the consistency of timing claim (e.g., 16 year old homicide rates in nonrepeal states increase rather than decrease approximately 16 years after Roe v. Wade). It also seems to undermine the mechanism because the decrease in crime among younger cohorts is roughly uniform rather than staggered (i.e., with 16 year olds decreasing first followed by

155 John J. Donohue and Steven D. Levitt, “Measurement Error, Legalized Abortion, and the Decline in Crime: A Response to Foote and Goetz," ibid., p. 433. 156 Elizabeth Oltmans Ananat, Jonathan Gruber, Phillip B. Levine and Douglas Staiger, “Abortion and Selection," The Review of Economics and Statistics 91.1 (Feb., 2009): 124-36, at 135 . 
17 year olds, etc.), which is more consistent with period effects than abortion. ${ }^{157}$

It might be argued that the raw data gestured toward in the final sentences of the previous two paragraphs is not as informative as the more rigorous regression analyses performed by Donohue and Levitt. But it also might be argued that these regression analyses obfuscate rather than reveal the facts. ${ }^{158}$ In light of this, it seems to me that the state-level evidence is suggestive but inconclusive.

IV.

Conclusion. The balance of evidence at the international evidence seems to me to militate against the Donohue-Levitt hypothesis as does the balance of evidence at the national level. The state level evidence is suggestive but inconclusive. Furthermore, the independent evidence for many if not all of the mechanisms that have been advanced to support the Donohue-Levitt hypothesis seems unpersuasive. In fact, many of these mechanisms would have predicted increased (rather than decreased) crime rates in the 1990s. Thus, it seems to me that the conclusion that ought to be drawn at present is that the Donohue-Levitt hypothesis is false.

Indiana University-Purdue University, Indianapolis

Indianapolis, Indiana

157 This point is made in Theodore J. Joyce, “Abortion and Crime: A review,” ibid., pp. $17-22$

158 Just this argument is made in Theodore J. Joyce, "Abortion and Crime: A review," ibid. 